This article was downloaded by: [82.19.199.199]

On: 13 October 2014, At: 07:19

Publisher: Routledge

Informa Ltd Registered in England and Wales Registered Number: 1072954 Registered

office: Mortimer House, 37-41 Mortimer Street, London W1T 3J H, UK

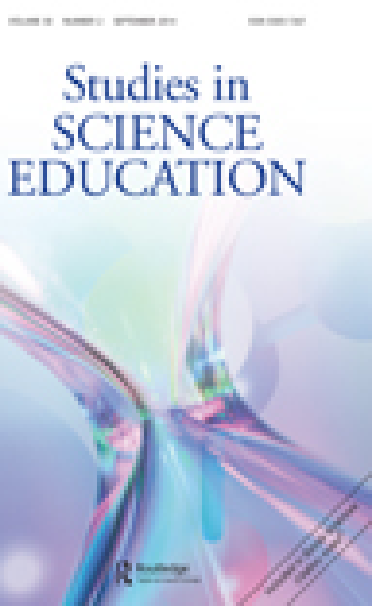

\title{
Studies in Science Education
}

Publication details, including instructions for authors and subscription information:

http:// www.tandfonline.com/loi/ rsse20

\section{Equity in informal science education: developing an access and equity framework for science museums and science centres}

\author{
Emily Dawson ${ }^{a}$ \\ a Department of Education and Professional Studies, King's \\ College London, London, UK \\ Published online: 22 Sep 2014.
}

To cite this article: Emily Dawson (2014) Equity in informal science education: developing an access and equity framework for science museums and science centres, Studies in Science Education, 50:2, 209-247, DOI: 10.1080/03057267.2014.957558

To link to this article: http:// dx. doi.org/ 10.1080/ 03057267.2014.957558

\section{PLEASE SCROLL DOWN FOR ARTICLE}

Taylor \& Francis makes every effort to ensure the accuracy of all the information (the "Content") contained in the publications on our platform. Taylor \& Francis, our agents, and our licensors make no representations or warranties whatsoever as to the accuracy, completeness, or suitability for any purpose of the Content. Versions of published Taylor \& Francis and Routledge Open articles and Taylor \& Francis and Routledge Open Select articles posted to institutional or subject repositories or any other third-party website are without warranty from Taylor \& Francis of any kind, either expressed or implied, including, but not limited to, warranties of merchantability, fitness for a particular purpose, or non-infringement. Any opinions and views expressed in this article are the opinions and views of the authors, and are not the views of or endorsed by Taylor \& Francis. The accuracy of the Content should not be relied upon and should be independently verified with primary sources of information. Taylor \& Francis shall not be liable for any losses, actions, claims, proceedings, demands, costs, expenses, damages, and other liabilities whatsoever or howsoever caused arising directly or indirectly in connection with, in relation to or arising out of the use of the Content.

This article may be used for research, teaching, and private study purposes. Terms \& Conditions of access and use can be found at http://www.tandfonline.com/page/termsand-conditions 
It is essential that you check the license status of any given Open and Open Select article to confirm conditions of access and use. 


\title{
Equity in informal science education: developing an access and equity framework for science museums and science centres
}

\author{
Emily Dawson* \\ Department of Education and Professional Studies, King's College London, London, UK \\ Informal science education (ISE) is a popular pursuit, with millions of people \\ visiting science museums, science centres, zoos, botanic gardens, aquaria, sci- \\ ence festivals and more around the world. Questions remain, however, about \\ how accessible and inclusive ISE practices are. This article reviews research on \\ participation in ISE through the lens of social inclusion and equity and suggests \\ that, as a field of practice, ISE is exclusive, with relatively little empirical or the- \\ oretical research on equity compared to 'formal' science education. This article \\ contributes to science education scholarship by exploring equity in ISE, bringing \\ together international research on ISE equity issues to examine what an access \\ and equity framework for ISE might entail. It draws on theoretical perspectives \\ from research on social justice, social reproduction and pedagogy to adapt a \\ three-part access framework, focusing in turn on infrastructure access, literacy \\ and community acceptance, to develop an access and equity framework for ISE.
}

Keywords: equity; access; social inclusion; informal science education; science centres; science museums

\section{Introduction}

Opportunities to learn about, engage with, question and critique science have become increasingly important in contemporary societies. Science and technology are embedded in people's lives in ways that are socially, culturally and politically significant, ranging from the everyday issues people grapple with, to societal decisions about the legislation of particular technologies, or revelations about scientific scandals and 'miracle breakthroughs' in the mass media (Bradu, Orquin, \& Thøgersen, 2013; Jasanoff, 1997; Michael, 2006; Nelkin, 1995). Given the degree to which science and technology are understood to affect our lives, accessible and equitable science education is clearly important to equip people with the tools, skills and information to negotiate contemporary life or enter scientific professions.

For many people school and the mass media remain the key contexts for encounters with science, scientific information and opportunities to think about, learn or question science (Ipsos MORI, 2014; Osborne \& Dillon, 2008). While schools and the mass media will doubtless continue to represent important sites for learning and engagement with science, a growing theme within the science education literature focuses instead on the roles played by science museums, science centres, zoos, aquaria, science festivals and other forms of so-called 'informal' or 'free-choice' science education (Falk \& Dierking, 2012; Stocklmayer, Rennie, \& Gilbert, 2010). Informal

*Email: emily.dawson@ucl.ac.uk 
science education (ISE) has been found to provide participants with opportunities to engage with science in ways that are inspiring, relevant and educational in both affective and cognitive terms (Bell, Lewenstein, Shouse, \& Feder, 2009; Phipps, 2010; Stocklmayer et al., 2010). Questions remain, however, about how accessible, inclusive and equitable ISE practices are.

In this article I examine international research about ISE through the lens of social inclusion/exclusion and equity. Despite appeals for socially inclusive ISE practice at different points in time (see e.g. Association of Science and Technology Centres, 1987; Atkinson, Siddall, \& Mason, 2014; Sandell, 1998), research suggests ISE remains a resource used by the more enfranchised groups of society (OECD, 2012). As such the benefits of ISE are only partially 'public'. Being unable to access ISE and the opportunities therein can be considered a form of marginalisation and social exclusion, especially in societies where engagement with science can be considered key for cultural participation, political voice and education (Harding, 2006; Young, 1990). It is important, therefore, to imagine what might be involved in developing ISE practices that support the ideal of science 'for all' rather than science 'for some'.

This article contributes to science education scholarship by exploring equity in ISE, through a review of international research on issues related to ISE participation, inclusion/exclusion and equity in practice, using a three-part access framework developed in computer literacy studies to examine what an access and equity framework specific to ISE might entail. The review carried out here is significant because there is a paucity of research on equity, inclusion and access to ISE, without which understanding the issues involved is limited. This article is therefore a step towards developing tools to explore, understand and, potentially, address inequity and exclusion in ISE, with the hopes of prompting discussion and, potentially, changes in practice in this important but sometimes overlooked aspect of ISE.

Starting with a review of research on patterns of participation in ISE, the main body of this article is structured around the three elements of an access framework developed by Porter (1998) and Grabill (1998) and explores equity in ISE through the concepts of infrastructure access, literacy and community acceptance. I use this conceptual framework to organise the review of research relevant to ISE inclusion, exclusion and equity issues carried out in this article, providing context by using examples of ISE practice and at the same time reviewing the relevance of the framework for understanding access and equity in ISE. I develop the access framework by drawing on theoretical perspectives from social justice (Fraser \& Honneth, 2003; Young, 1990), the reproduction of social disadvantage (Bourdieu \& Passeron, 1990) and pedagogy (Freire, 1998; hooks, 1994; Vygotsky, 1978) to outline an access and equity framework adapted for ISE research and practice.

\subsection{Terminology}

It is worth briefly discussing language and terms at this point, firstly in terms of ISE and secondly, people. It is useful to distinguish between different kinds of ISE and learning since the categories used by different researchers vary and are contested within the ISE literature (see e.g. Bell et al., 2009; Falk, 2002; King \& Dillon, 2012; McCallie et al., 2009). For the purposes of this review, informal science learning will be understood as something that can happen anywhere, at any time, 'in the wild' as it were. This review focuses on ISE rather than informal science learning. 
ISE is understood here as institutionally framed and located in organised, designed environments that range from science festivals, to aquaria to museums and science centres, staffed by professionals. Such places will be referred to as informal science learning environments (ISLEs) in this article.

It is also important to note that the implications of identifying and representing people or groups as 'other' - whether as 'non-participants', 'non-visitors', 'new audiences' or 'excluded' - are problematic and risk reifying certain groups as themselves at fault (Bell et al., 2009; Levitas, 2004). In using such terms, as I do in this article, I acknowledge there is a delicate balance between the importance of recognising disadvantage and attempting to understand how disadvantage arises within ISE on the one hand, and on the other, the potentially damaging use of labels and terms that mark certain groups and people as different.

This paper draws predominantly on a view of people's identities as fluid, contested and performative, based on the work of Holland, Skinner, Lachiotte, and Cain (2001), Butler (2006), Lawler (2014) and Hall (1996). From these perspectives, identity is understood as a process rather than a product and comprised of multiple interrelated facets affected by experience. Thus, as described in more detail later, identities are comprised of demographic features, termed 'social positions' by Holland et al. (2001), such as gender, 'race'/ethnicity or age, which are some of the more stable elements of identity, as well as more fluid aspects of identity, such as performances in public roles (Lawler, 2014).

While the concept of identity is used in different ways across a wide range of fields in ways that would be hard to do justice to in this paper, I mention identity here because although the focus of the paper is on ISE, equity, pedagogy and social justice, the notion of identity underlies these issues. In essence, as the following section will show, large data-sets on participation in ISE suggest demographic factors, or social positions, are a key feature of who does and does not access ISE. While it has been argued that social positions are not key aspects of identity as far as ISE visiting is concerned, where instead what are sometimes termed 'psycho-social' features of identity have been seen as more important (Falk, 2009, 2011), the trends in the large data-sets call such arguments into question (see also Dawson \& Jensen, 2011). Thus, it is important to outline, albeit briefly, how identities, and social positions in particular, are framed here, as a key but fluid aspect of identity that appears to influence patterns of participation in ISE at a national scale.

\subsection{Exploring patterns of participation in ISE}

ISE is a popular pursuit, with millions of people visiting science centres, museums, zoos, botanic gardens, science festivals and more around the world (National Science Foundation, 2012; OECD, 2012). As Duensing's (2006) qualitative, long-term study of science centre practices in different countries suggests, while local practices may differ, the notion of a 'science centre' has spread internationally. Similarly, an international survey of science festivals carried out by Bultitude, McDonald, and Custead (2011) found that while such activities remain concentrated in Europe, there is significant international growth of such activities, with more than 5.6 million people worldwide taking part.

In the UK, for example, according to a 2014 report on public views of science, of the people surveyed 'two-thirds $(67 \%)$ have been to at least one of the sciencerelated leisure or cultural activities asked about in the survey in the previous year' 
(Ipsos MORI, 2014, p. 109). The activities asked about were science talks and activities outside of school or university classes, visits to science centres, science museums, zoos, aquaria, nature reserves, planetariums and science festivals. Of these activities, nature reserves, zoos and aquaria, museums and science centres were, in that order, the most popular (Ipsos MORI, 2014).

While the inclusion of nature reserves as a category in the 2014 survey increased the total proportion of participating adults, ${ }^{1}$ these data still support the results of an earlier version of the same survey that found over half the surveyed public were involved in the science activities the survey asked about (Ipsos MORI, 2011). The popularity of science activities in the UK is further backed up by data from the British science centres network, ${ }^{2}$ which showed that science centres were visited more than libraries, art galleries or theatres in 2005-2006 (Ecsite-UK, 2008).

Despite their apparent popularity, examining who visits ISLEs in demographic terms suggests that their appeal is not as broad as might be hoped if the goal is access to ISE resources for the general public. Relatively little is known about why and how patterns of non-participation in ISE exist and persist, a concern raised by others in the UK (Atkinson et al., 2014; ASDC, 2010; Wellcome Trust, 2008), and echoed across Europe (Massarani \& Merzagora, 2014) and in the USA (Bell et al., 2009). Patterns of non-participation can, however, be inferred by exploring who is missing from data on participation in ISE.

Staying with the UK as an example, the fifth of the population highlighted in the Ecsite-UK (2008) report as science centre visitors were more than half female, comprised of large numbers of young people, those visiting with their schools $(17.3 \%$ for the nine millennium funded science centres, and $10.6 \%$ for the six nationally funded science museums that participated in the study) and those visiting with their families (between $31 \%$ and $40 \%$ of science centre visitors for institutions involved in the study). These findings suggest that ISE users are young people, facilitated by their schools or by their parents, typically mothers, a pattern echoed in the report commissioned by the Department for Business, Innovation and Skills and research on mothers' family roles (Ipsos MORI, 2011; Reay, 1998). Research also suggests that science centre visitors in the UK are usually middle-class people from White British ethnic backgrounds (Ipsos MORI, 2011, 2014; Wellcome Trust, 2008).

Research on museum visitors in the UK highlights similar patterns; most visitors to museums are from the dominant White ethnic majority, from upper and middleclass groups, ${ }^{3}$ educated to degree level, female, without a disability and based in urban areas (Department for Culture, Media and Sport, 2011; Ipsos MORI, 2001, 2006, 2014). What this means is that in the British context ISE participants are drawn from White ethnic backgrounds, middle and upper classes, live in cities and visit with their families or schools. Clearly a broad range of practices, places and professionals exist within ISE; however, research suggests the same kinds of people access and use these different resources (Falk et al., 2012). Thus, while the visitor profiles of individual science festivals, zoos or science museums may vary, taking a step back to look across the system more broadly highlights the overlap between the 'partial public' of ISE and advantaged social groups. Descriptive visitor data suggests, therefore, that rather than ISE providing valuable opportunities for all, such opportunities are predominantly used by the more privileged groups of UK society.

In the USA, similar patterns of participation in ISE have been identified. A 2012 report from the National Science Foundation found that while $61 \%$ of Americans had visited an ISE institution, participation was marked by certain aspects of social 
position; families with young children were more likely to participate, as were people under the age of 65 , people with more educational qualifications and those with higher incomes (2012). These last two issues, educational qualifications and income, can be interpreted as proxy measures for social class status. These data suggest that in the USA, ISE inaccessibility and non-participation are marked by age (with older people participating less), family status (those without children participate less) and social class (those in working-class and lower socio-economic positions participate less). While it is interesting to note that ethnicity and gender are not mentioned in the US data, the patterns of inaccessibility and non-participation in ISE are markedly similar to those identified in the UK.

At the international scale while opportunities to participate in ISE activities appear to be increasing, little data is available about who participates (Falk et al., 2012). For example, across Europe participation in ISE opportunities via science centres and museums is a widespread phenomenon: '35 million European citizens, of whom $37 \%$ are youngsters, visit science centres and museums in Europe every year - i.e. about $10 \%$ of the whole population of Europe' (European Commission, 2004, pp. 161-162). Within this picture, however, data about who participates is hard to identify at the level of individual countries. Data from the OECD suggests that participation in what they describe as 'non-formal education' (2012, p. 416), which included all educational activity outside schools and universities, is marked by social position. In particular, age and social class were key issues affecting nonparticipation in non-formal education; older adults and less educated adults participated less than other people in non-formal education opportunities.

While it is not possible to determine levels of non-participation specific to science centres, museums or other kinds of ISE from the OECD data, these data align with the patterns identified thus far that participation in non-formal education is socially narrow and marked by social position. In other words, descriptive data from the UK, USA, Europe and the OECD suggests that access to ISE and participation in ISE activities are socially stratified and those in the more advantaged social positions are more represented amongst visitor figures. To look at this picture in reverse, these data suggest that people from lower socio-economic groups, from minority ethnic groups, older adults, and those living in rural areas and away from their families are unlikely to use ISE. Exclusion from ISE therefore appears hierarchical (because it is patterned by social disadvantage) and intersectional (through the overlap of social disadvantages). Thus the field of ISE evidently has equity issues that need to be addressed.

\subsection{Empirical research on social inclusion/exclusion in ISE}

A significant challenge in trying to understand why and how patterns of partial participation exist and persist in ISE is, as suggested earlier, the limited amount of empirical or theoretical research on the subject. Research on ISE has tended to focus on those who do participate and what benefits that participation may provide for them. For instance, we know a lot about what supports students during ISLE visits from research in different countries. A longitudinal interview study of 14-15-yearold Israeli students exploring their ISLE experiences and memories found students were able to link content from ISLE visits to school science, especially when supported by ISLE staff facilitation (Bamberger \& Tal, 2008). These findings are similar to those of DeWitt and Osborne (2010) whose interview study with younger 
students (ages 9-11) in the UK found they were able to recall and explain science content encountered during ISLE visits, particularly when facilitated by a teacher.

Further evidence about how students learn in ISLEs can be gleaned from a design-based research study carried out in the USA (Mortensen \& Smart, 2007). The study found a worksheet designed to help 8-11-year-old students on school trips to a museum supported students developing links between the museum and school science content (Mortensen \& Smart, 2007). Finally, in China, exploratory research at the Shanghai Science and Technology Museum suggests that the History, Philosophy and Sociology of Science approach they have developed to frame science in their science education programme helps students (across age groups) connect museum and school science (Song \& Zhao, 2012). These studies represent only a small sample of ISE research. Notably, however, the studies share research interests as well as similar findings, such that taken together they suggest students learn better in ISLEs when provided with clear forms of support.

While such research provides valuable insights about existing visitors, the risks of inward-facing research are that it may, quite literally, be unable to look outside the box. In other words, that ISE research is constrained because of a tendency to 'consider only those who are in the system at a given moment, excluding those who have been excluded from it' (Bourdieu \& Passeron, 1990, p. 159). Thus, while there is a great deal of empirical research on how visitors to museums, science centres, aquaria or other ISLEs behave, learn, socialise or recall their visits (see for further examples Falk, 2009; Packer, 2008; Tunnicliffe, 2008), there is comparatively little research on questions of access, inclusion/exclusion, 'non-visitors' or 'new-audiences'.

The most comprehensive mapping of the available ISE research to date can be found in Bell et al. (2009), Fenichel and Schweingruber (2010) and Falk et al. (2012), all of whom reviewed the literature; the first two concentrated on the USA and the third reviewed international research. The Falk et al. (2012) research review is revealing in terms of mapping research focuses and gaps. A structured literature review was carried out using two academic databases ${ }^{4}$ with the search terms 'free choice learning' and 'informal science learning' ${ }^{5}$ between 1980 and 2011, resulting in 553 articles. Re-examining those 553 articles through the lens of inclusion confirms the limited amount of research on the subject of inclusive practice and ISE, science communication and 'science in public' more broadly.

Of the 553 articles identified by Falk et al. (2012) only 27 addressed participants, visitors or audiences who could be considered disenfranchised in some way; 8 focused on minority ethnic students, 10 on female students, 3 on minority ethnic families, 2 on female, minority ethnic students, 2 on minority ethnic groups, 1 on low-income students and 1 on low-income families. Over a 31-year period of internationally sampled, albeit English language papers, this is a surprisingly low number, especially given that concerns about equity in museums, cultural participation and science date back at least 30 years (Association of Science and Technology Centres, 1987; Gurian, 2006). Within the 553 articles, research on more specific issues of physical inclusion, such as the needs of deaf or partially sighted visitors, was not identifiable.

Notably, 279 of the 553 articles were published by US authors, while 77 were from the UK, 31 were from Australia and a further 22 were from Canada. While research from a number of other countries was represented, ${ }^{6}$ this pattern suggests the available research is largely based in the USA, making international comparisons 
difficult, especially on issues such as equity, which have been less attended to. Although even a structured literature review will inevitably miss some papers, the Falk et al. (2012) study nonetheless suggests that questions of inclusion and exclusion in ISE are underresearched and questions about ISE participants narrowly framed.

\subsection{Conceptual approaches to social inclusion/exclusion in ISE}

To date where attention has been given to issues of social inclusion/exclusion, equity and social justice within ISE, the tendency within the field has been one described as 'assimilation' (Bell et al., 2009). Reviews of ISE practice within the UK (Falk et al., 2012) and the USA (Bell et al., 2009; Fenichel \& Schweingruber, 2010) suggest that with few exceptions, the majority of attempts at inclusive ISE practice can be understood as assimilationist in their approach. These research reviews suggest that while ISE practitioners were by and large signed up to addressing issues of equity when asked, 'doing equity' in practice appeared to be significantly harder.

The concept of assimilation can be traced back to the education literature as well as the literatures on social justice, social inclusion and policy debates (Lee, 1999; Ogbu, 1992; Yosso, 2005; Young, 1990). Assimilation refers to attempting to increase inclusion in a practice (such as ISLE visiting) without considering the cultural, social, linguistic or other changes that may be required for that practice to be appealing, accessible and equitable (Bell et al., 2009; Fenichel \& Schweingruber, 2010). In other words, an assimilationist approach to inclusion and equity in ISE rests on providing existing science learning opportunities, as they are, to 'new' or underrepresented groups. In the science education literature the history and practices of privileging scientific knowledge above other kinds of knowledge have been described as assimilationist where attempts have been made to replace other knowledges, perspectives or practices with those of 'science' (Lee, 1999; Stanley \& Brickhouse, 2001). Such practices have been critiqued as deficit oriented both in terms of relationships between publics and science in general (Irwin \& Wynne, 1996) and in terms of relationships between socially marginalised groups and science education in particular (Lee \& Buxton, 2010).

Other arguments about the potential of ISE to be inclusive have suggested that the 'informality' of such learning and engagement opportunities, that is, their lack of government-led curricula, assessment practices and voluntary attendance, affords visitors the opportunity to learn in ways that best suit their own preferences, expectations, interests and prior experiences (Dierking \& Falk, 2009; Stocklmayer et al., 2010). It would, however, be problematic to assume that any designed learning environment was without explicit and implicit biases that constrain some learners while benefitting others. For example, research carried out in Canada and the USA suggests that young people and families from minority ethnic backgrounds can face cultural and linguistic difficulties in ISLEs (Ash, 2004; Rahm, 2008). Furthermore, research from the UK found people from socio-economically disadvantaged, minority ethnic backgrounds faced significant challenges feeling comfortable in, engaging with and learning science from ISLEs (Dawson, in press). Thus, in the case of ISE, while, at best, some ISE opportunities may well afford certain kinds of visitors with fantastic resources amidst which they can create fascinating and personalised learning experiences for themselves, research suggests that 'other' kinds of visitors appear to be significantly less able to do so. 
While research from the science education literature has made inroads into how some of the more stable features of identity, such as the social positions of gender, minority ethnic background, linguistic background and poverty, are understood and map onto student experiences in the classroom (see e.g. Carlone, 2003; Lemke, 2001), little research along such lines has been carried out on ISE. For example, Carlone and Johnson's (2007) longitudinal interview study with women from minority ethnic backgrounds studying science at university in the USA suggested that being able to develop a 'science identity' played a crucial role in participants' success in science. In other words, the extent to which participants were able to identify with science, other scientists and scientific practices and were in turn recognised by others as a 'science person'. Drawing on research about gender, 'race'/ethnicity, language and socio-economic status in 'formal' science education might be useful for those involved in ISE, not least in terms of thinking through how to develop accessible, inclusive and equitable experiences that support the development of 'science identities' in ISEs? Reviewing the research on equity and social inclusion/exclusion in ISE therefore suggests that this is an underresearched area, both empirically and theoretically, limiting the potential for developing more inclusive ISE practices.

\section{Applying an access framework to understanding equity in ISE}

Developing a more equitable approach is a key challenge for ISE. To try and outline the issues involved, in this article, I draw on the access framework developed by Porter (1998) and Grabill (1998) around computer literacy, since the 'outside the classroom', community learning perspective they adopt is practice-based and, as a result, useful for understanding access and equity issues in ISE practices. Porter suggests three dimensions to understanding access: (1) infrastructure access, (2) literacy and (3) community acceptance. In what follows I apply Porter's (1998) three-part framework to the issue of equity in ISE. In addition, I develop the three-part access framework by drawing on concepts from the work of Young (2000) and Fraser (2003) on social justice, Bourdieu (Bourdieu, 1984; Bourdieu \& Passeron, 1990) on the reproduction of disadvantage, sociocultural constructivist pedagogy (Bruner, 1966; Vygotsky, 1978) and critical pedagogy (Freire, 1998; hooks, 1994), to outline a theoretically informed approach to understanding inclusion, access and equity in relation to ISE.

\subsection{Infrastructure access}

The first dimension of inclusion in and exclusion from ISE addressed here is whether people can access the institutions, festivals or other resources involved. As shown above, data on who does and does not use ISE suggests it is only partially public. In other words, that certain groups of people do not use science centres, museums or other ISLEs. Porter (1998) describes this basic and underlying aspect of inclusion as infrastructure access. Infrastructure access refers to the extent to which people can access the institutions and resources in question. For ISE this would include the physical manifestations of the venues and institutions involved, such as, for example, their location, entry costs, physical entry accessibility, but might also include less literal issues such as marketing strategies, who is and who is not considered as target audiences, or the kinds of staff recruitment processes in place. 
Porter (1998) suggests that the issue of infrastructure access also includes questions of power-sharing. Specifically, Porter (1998) argues that access to involvement in decision-making processes is a crucial element of infrastructure access, including involvement in development and design processes. To explore this within ISE this would include looking at the members of institutional committees or boards, and the roles within them, as well as the extent to which publics beyond those 'typical' of ISE are involved with programme or exhibit development processes.

\subsubsection{Limits to infrastructure access}

In examining infrastructure access to ISE through research, a contradictory picture emerges. ISE institutions and their representatives appear to be signed up to an equity agenda and numerous inclusion and participatory projects have been carried out. In the USA, calls for widening participation in ISE date back to the 1980s (Association of Science and Technology Centres, 1987; Gurian, 2006) and beyond (Fenichel \& Schweingruber, 2010), while in other countries, such as Brazil and Tunisia, the underlying ethos of science centres, science museums and science communication has been directly linked to social inclusion (Tait Lima, das Neves, \& Dagnino, 2008; Zouaoui, 2007). Despite this, however, the profile of people using ISE has changed little over several decades.

Recent research in the USA suggests ISE practitioners felt committed to developing equitable institutions for visitors and staff alike, but understood equity in a variety of, sometimes conflicting, ways (Feinstein \& Meshoulam, 2014). Similarly, research on ISE professionals views and practices in the UK suggests tensions are inherent in how equity and inclusion are understood (Tlili, 2008). Of course, it would be hard for interviewed ISE practitioners to suggest they were 'against' equity, given the strongly positive values associated with it. Nonetheless, despite the apparent importance of equity within ISE, the translation of equity and inclusion from idealised concepts into ISE practice may be less than straightforward.

A move towards increased power-sharing and participatory approaches can also be identified in research on some contemporary ISE practices (Bandelli \& Konijn, 2012), thus reflecting the second aspect of Porter's (1998) infrastructure access. While increasingly ISE institutions include community advisory panels or committees as part of institutional governance or project development, the extent to which such approaches enable or resist power-sharing has been questioned (Bandelli \& Konijn, 2012; Bandelli, Konijn, \& Willems, 2009; Lynch, 2011). Similarly, although calls for participatory practice in various elements of ISE activity have increased and have been specifically linked to issues of equity and widening participation (see for example Golding, 2009; Simon, 2010), this appears to have been difficult in practice.

Two projects, one from Vienna and one from London, provide useful examples of attempts at inclusive ISE practice, but illustrate too the tensions around infrastructure access that arise in such projects. The project from Vienna, Austria, followed an 'outreach' approach in that rather than attempting to attract different audiences to an ISLE, three ISLE-like spaces (called Knowledge Shops) were set up inside vacant shops in particular neighbourhoods (Streicher, Unterleitner, \& Schulze, 2014). In other words, the project took ISE into communities identified as 'socially disadvantaged' and 'difficult-to-reach' (Streicher et al., 2014, pp. 1 and 3). Notably, the project disrupted some elements of infrastructure access by changing locations and 
venue 'type', including translations into a minimum of five languages, no entry costs and consultation with community representatives to develop relevant content.

The project from London's Science Museum, in the UK, aimed to address the power-sharing element of infrastructure access by involving participants from outside the 'typical' ISLE profile in the project development (Foggett, 2008). The project sought to develop equitable, inclusive science learning processes, through working in a participatory manner with people that the museum had identified as 'non-visiting groups' (Foggett, 2008, p. 3), in this case the African-Caribbean community in London. The project was noteworthy for inviting a panel of community members to consult on and influence the programming of four events related to the bicentenary of the abolition of the Slave Trade Act of 1807, taking an important step towards attempting to address the racist legacy of museums with historic scientific collections (Lynch \& Alberti, 2010).

While both projects were clearly positive in a number of ways, tensions exist in whether the problems of ISE infrastructure access were challenged or changed through their work. Despite meeting many of the individual project aims, the critiques levelled by Lynch $(2001,2011)$ at participatory museum projects can be applied to these two projects. Firstly, power-sharing was limited, for example, despite the influence of the community consultations, both projects were ultimately controlled by the ISE institution. Secondly, participants were framed as 'other' and finally, the role of equity was positioned as a peripheral rather than a core element of the institutions, specific instead to a particular project (Foggett, 2008; Lynch, 2011; Streicher et al., 2014). Creating spaces to experiment with and develop more inclusive ISE practices is clearly important; questions remain, however, about the extent to which projects such as these are able to change institutional practices or shift patterns of participation in ISE outside the time frames and spaces of specific activities.

Although these two examples cannot be taken as representative of the broader field of ISE practice, they suggest that despite resource-intensive efforts and the goodwill of ISE practitioners, the development of projects designed to address infrastructure access and include participatory approaches has been limited. Questions remain, therefore, about why infrastructure access remains a problem for ISE despite evidence to suggest that ISE institutions and their representatives are concerned about equity and do develop practices intended to address equity concerns. In other words, why has there been so little change to patterns of participation?

\subsubsection{Extending the concept of infrastructure access}

Porter's (1998) concept of infrastructure access can be extended by drawing on theories about educational and cultural participation, the reproduction of social disadvantages and oppression which provide a further degree of explanatory power. The data on who does and does not use ISE suggests that ISE participation is a socially stratified activity, with participation marked by the social position aspects of identity. Social positions are highlighted again and again as crucial identity factors in research on educational, political and cultural participation (Bourdieu, 1984; Bowles \& Gintis, 1976; Shanahan, 2009; Young, 1990). Theories about identity and social positions such as gender, ethnicity and class, and their social roles are contested and come with their own tensions and histories (Skeggs, 1997). These demographic characteristics are, however, important because they illustrate the importance of 
social positions for identity because 'social position has to do with entitlement to social and material resources and so to the higher deference, respect, and legitimacy accorded to those genders, races, ethnic groups, castes, and sexualities privileged by society' (Holland et al., 2001, p. 271).

Educational and cultural participation have been explicitly linked to issues of identity and social position (in particular, ethnicity, gender and class) and the reproduction of social inequalities (Harding, 2008; hooks, 1992, 1994; Yosso, 2005; Young, 1990). Moreover, research suggests that people occupying the overlap between identity-based social positions (being female, elderly and homosexual, for example) can face particular disadvantages in terms of educational, cultural and social equity. Intersectional approaches exploring overlapping social positions have been used to explore the relationships between cultural consumption, ethnicity, age and class (Bennett et al., 2009; Trienekens, 2002), gender and education (Dumais, 2002; Mickelson, 2003), and the relationships between gender, ethnicity, class and education. Thus research from a number of different fields supports the argument that elements of identity, specifically in this case social positions, and the advantages or disadvantages they confer, play important roles in access to resources, such as, in this case, ISE. Understanding the relationships between power, people, institutions and society may be key for understanding equity in ISE.

Bourdieu's work on the social roles played by educational and cultural institutions found that they preserved the advantages of the powerful and discouraged the participation of people from non-dominant groups, as a result, keeping them at a disadvantage (Bourdieu \& Darbel, 1991; Bourdieu \& Johnson, 1993; Bourdieu \& Passeron, 1990). Through the development of a trio of concepts - habitus, field and capital - Bourdieu traced the practices through which educational institutions such as schools and universities and cultural/educational institutions such as art galleries and museums enhanced the cultural capital of those from empowered groups, while limiting the extent to which those from disadvantaged groups were able to access that cultural capital, or even the institutions themselves. While Bourdieu primarily focused on the role of social class as a feature of identity, as Gayo-Cal has argued, 'if one wants to understand why people exhibit particular patterns concerning leisure, Bourdieu's approach is still useful, but other factors [...] like age, ethnicity and gender, also need to be considered' (2006, p. 187). Given that ISE venues can be understood as both educational and cultural institutions, to what extent are they embedded within a system that reproduces social disadvantage through inaccessibility?

To explore how Bourdieu's perspective on the reproduction of social disadvantage could apply to ISE, an example of a specific ISE project that aimed to increase access and equity for 'non-visitors' is useful. The Creative Canals project was carried out at the Science Museum in London in 2005 (Hooper-Greenhill et al., 2007). As part of the project a group of Bangladeshi women from an area of London described as 'deprived' were recruited via links with a community organisation that provided English language teaching (Hooper-Greenhill et al., 2007, p. 102). The project was found to offer participants opportunities to practise their English language skills and enjoy a day out. In this sense participants may have developed some cultural capital (English language skills and information about the museum). The research noted, however, that the project made little difference to the core activities or audiences of the museum, to the participants' interest in visiting ISLEs again or their longer-term access to ISE (Hooper-Greenhill et al., 2007). 
Within this project participation was enacted under special circumstances for the Bangladeshi women, potentially reinforcing their expectations (and habitus) that ISE was not 'normally' for them. The research described the constraints on ISE participation within the women's lives, including structural issues of free time and competing commitments that the project was unable to address. Furthermore, the project was driven by museum staff and their aims, rather than the needs, aspirations or motivations of the community group. In this way the infrastructure of ISE appears to have remained largely inaccessible, while participants' experiences of ISE practice may have contributed to a sense of being peripheral rather than core audiences (Hooper-Greenhill et al., 2007; Lynch, 2011). This process can be mapped against Bourdieu's cycle of the reproduction of social disadvantage (Figure 1).

As outlined in Figure 1, the relationships between ISE practices, ISE infrastructure and the attitudes, behaviours or habitus of those who do not usually participate in ISE can be understood by drawing on Bourdieu's perspective on the reproduction of social disadvantage (Bourdieu \& Passeron, 1990; Bourdieu \& Wacquant, 1992). Although at first glance there appear to be contradictions in ISE practice - access and inclusion projects are carried out but the profile of ISE participants does not change - these contradictions can be understood if such projects are positioned within a cycle of social disadvantage, where the infrastructure of ISE remains inaccessible and the habitus of 'non-visitors' does not change. Thus, inaccessibility and inequity can be seen as a resilient, entrenched feature of the field of ISE.

Given the argument made so far - that ISE can reproduce disadvantages for people in certain social positions - why is access and inclusion in a potentially damaging system important? As suggested at the start of this paper, the role of science is sufficiently central to the different cultural, social, political, educational and economic aspects of contemporary lives that being unable to access opportunities to learn about, participate in, critique or otherwise enjoy science can be understood as a form of marginalisation. ISE represents a potentially empowering set of resources

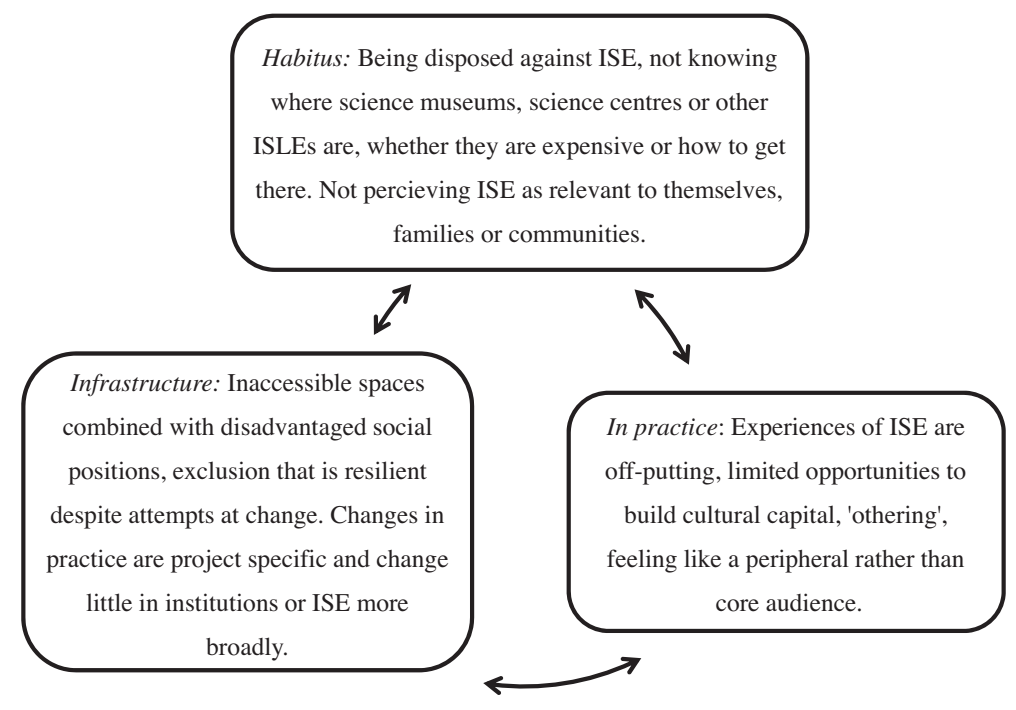

Figure 1. Reproducing disadvantage in ISE. 
that could disrupt rather than reproduce cycles of disadvantage if the challenges represented by becoming more accessible, equitable and inclusive can be discussed, experimented with and ultimately addressed. In advocating change I do not mean to suggest that such changes are easy, but argue that such changes are important and require a better understanding of the issues involved (both problems and potential solutions) than is currently available in the literature.

\subsubsection{Redistribution and recognition in ISE infrastructure access}

To understand how the reproduction of social disadvantage is resilient in ISE, despite practitioners being found to be sensitive to equity issues (Feinstein \& Meshoulam, 2014; Tlili, 2008), Young's (1990) work on social justice and Bourdieu's notion of symbolic violence are helpful. The concept of symbolic violence was developed by Bourdieu to describe how disadvantage is reproduced in ways that are institutionalised, unclear and hard to combat (Bourdieu, 1991). Young's (1990) work on oppression takes this idea further and suggests that symbolic violence can develop in institutions and fields of practice through the taken-for-granted practices, customs and thoughts, none of which are explicitly intended to harm, exclude or disadvantage. She argued that inequitable practices could be understood as a form of oppression, stating that:

oppression also refers to systematic constraints on groups that are not necessarily the result of the intentions of a tyrant. Oppression in this sense is structural, rather than the result of a few people's choices or policies. Its causes are embedded in unquestioned norms, habits, and symbols, in the assumptions underlying institutional rules and the collective consequences of following those rules. (Young, 1990, p. 41)

Thus, drawing on Young (1990), the reproduction of social disadvantage in ISE has less to do with purposefully exclusive practices on the parts of ISE institutions and their representatives, than with the ingrained values, systems and behaviours of ISE practitioners, their visitors and their 'non-visitors', as well as society more broadly.

Young (1990) argued that oppressive cultural and educational practices render non-dominant groups invisible by 'othering' the cultures, practices and knowledges of people from non-dominant groups, which she describes as a form of cultural imperialism. In this sense while the redistribution of ISE opportunities via changes to infrastructure access is clearly important, representation is also key, not only in terms of who or what is represented in ISE, but how such representations frame their content and whether differences are respected. Building on the Bourdieusian analysis of ISE practices outlined above, changes to infrastructure access may rest upon 'new audiences' finding culturally relevant content in science centres or museums and feeling welcome within them, rather than invisible or 'othered'.

To understand how groups can be written out of science stories in ISE, it is useful to look at practice. In the development of an exhibition about human evolution at the Natural History Museum in London in the mid-2000s, for example, it was notable who was and was not highlighted in the way the story was told. The exhibition being developed focused on the discovery of the transition fossil 'Lucy' in the Afar region of Ethiopia. The story of the fossil was retold as academic rivalry between two White, Western men (Richard Leakey and Donald Johanson). In this version, the Afar tribespeople who carried out much of the archaeological dig as members of the team and their homeland were invisible ${ }^{7}$. 
Another example can be drawn from the South Africa Museum in Cape Town where, in 2012 a gallery of dioramas about life in the Western Cape represented Black South Africans in ways that described their work and the artefacts produced in an ethnographic manner as 'other'. This exhibition so clearly represented the people it described in a problematic manner that a prominent and more recent exhibit label read as follows: 'Out of touch? This gallery was commissioned in the 1970s and since that time approaches to exhibiting African culture have changed'. ${ }^{8}$ Despite the additional, more culturally and politically sensitive exhibition interpretation, in a neighbouring gallery the work and artefacts produced by a different group of people were presented as 'science', the people themselves were not represented through models or images, and the exhibition was not prefaced with revisionist exhibit text. Such examples highlight the tensions involved in representing 'difference' within ISE, even in institutions that could be described as culturally sensitive.

Given the political background of South Africa, examples drawn from a museum in Cape Town could be considered extreme; research suggests, however, that issues of representation and difference in ISE emerge in a number of countries. Garibay (2009), for example, found people from Latino communities in the USA felt ISE institutions were unwelcoming and the lack of representation of their own cultures and languages was particularly problematic since this led to a sense that ISE was not culturally relevant for them. Research carried out elsewhere, for example, an interview study with female Māori scientists in New Zealand exploring early experiences of science (McKinley, 2008), a study of a series of ISE programmes in Native communities in the USA (Mack et al., 2012) and a qualitative study of a multicultural ISE programme with Jewish and Arab students in Israel (Tal \& Alkaher, 2010), found that people from non-dominant backgrounds struggled with ISE experiences that felt culturally distant or irrelevant. Taken together these studies suggest that across different contexts, different groups struggle to see ISE and ISE institutions as culturally relevant because of the issues to do with power, language, content and representation.

The key point here about social justice and equity is that representations of culture, knowledge, values, practices or attitudes in ISE are rarely universal or 'natural', but instead draw upon the dominant forms of culture, knowledge and so on, while rendering other forms of culture, knowledge, values, practices and attitudes invisible (Fraser, 2003; Young, 1990). From this perspective, being able to critically reflect on ISE practices and recognise difference alongside concerns over the uneven distribution of infrastructure access is crucial.

Fraser argues that for a dualist view of social justice 'the goal, in its most plausible form, is a difference-friendly world, where assimilation to majority or dominant cultural norms is no longer the price of equal respect' (2003, p. 7). In other words, improving equity and access in ISE requires more than providing existing science education programmes to different kinds of people (assimilation and redistribution), but taking difference into account and delivering difference-appropriate science education programmes (recognition and redistribution). Thus while people may well continue not to participate in ISE, equitable infrastructure access means that everyone is entitled to be able to choose to go (or not) and to have a meaningful, culturally relevant ISLE visit where their own communities and cultures are respected and represented. 


\subsection{Literacy: understanding the 'rules of the game' in ISE}

Access to the infrastructure of ISE entails more than physical access alone. People need to be able to understand what to do once they are inside a science centre, museum or zoo and, at best, how to maximise the opportunities for enjoyment, learning or socialising therein. Porter (1998) proposed the concept of literacy to refer to being able to use an infrastructure and the resources it represents to one's own advantage. For ISE this point is well suited to questions around whether exhibits, texts, objects, interactive exhibits, staff facilitation styles or whole institutions require visitors to have a sense of a specific 'ISE' literacy (Bain \& Ellenbogen, 2002; Hooper-Greenhill, 1995; Schlereth, 1992). In other words, to draw on Bourdieu and Wacquant (1992), that in terms of habitus, people have a 'sense of the game', that they can use the infrastructure to their advantage and access the resources within an ISE institution.

\subsubsection{Conceptualising ISE literacy}

Porter's (1998) perspective on literacy is useful for understanding how the epistemic practices of an ISE institution can be differently interpreted by people as a result of their prior experiences. A useful example comes from research carried out by Wertsch, Minick, and Arns (1984) in Brazil. Wertsch et al. (1984) explored the differences in learning and teaching practices between two groups of six-year-olds; one group was facilitated by their (working-class) mothers and one by (middle-class) teachers. The two groups of adults facilitated the learning exercise in markedly different ways and the learning opportunities afforded to the children differed as a result. The study found that the mothers brought their experiences of work to the situation, treating the learning exercise as something to be done with maximum efficiency, carrying out much of the task themselves. In contrast, the teachers saw the exercise as educational, encouraged the children to do the majority of the task and treated mistakes as a useful part of the experience. Wertsch et al. (1984) concluded that previous social experiences and cultural expectations significantly influenced how people respond to learning environments.

The example from Wertsch et al. (1984) is particularly pertinent for ISE because it shows how differently the same learning opportunity can be understood and enacted. Unlike school classrooms, science centres, museums and other ISLEs are not always able to rely on participants' interactions with trained staff to facilitate learning for the majority of visitors. Thus learning hinges to a greater degree on individual, family or peer literacy and ability to grasp the 'right' thing to do when faced with an exhibit as well as the extent to which the exhibit is designed to be accessible. Knowing what to do hinges, in turn, on the previous experiences afforded by someone's social position and lifestyle.

Research on computer-based interactive exhibits in ISLEs suggests, for example, that the 'rules' of interaction are complex both logistically (hitting the right part of a touch screen, aligning your body correctly for a camera) and conceptually (tasks often follow a teaching pattern of 'elicit action' and 'response from interactive' based on understanding scientific content) (Heath, Lehn, \& Osborne, 2005). The behaviour required to use such exhibits in the 'right' way is embedded in the interactive exhibit, which will not work without the right steps being carried out. In this sense, museum literacy - the ability to understand how to use or look at an exhibit 
- is implicit within the design, or, as Macdonald has argued, following Hall, exhibits are encoded with meaning which is more or less accessible, more or less translated or reworked, depending on how visitors decode them (Hall, 1980; Macdonald, 1998; Rice, 1992). Furthermore, research suggests that the actions required for ISE exhibits to 'work' have a cultural component, thus an interactive may require different steps in a science centre in Brazil, compared to a similar exhibit in a museum in France (Duensing, 2006). Thus the encoding and decoding required to make sense of and learn from an ISE exhibit may require culturally specific insights about the 'right' things to do.

Understanding what to do in an ISE institution or activity goes beyond museum literacy and knowing how to engage with a learning opportunity. Attention should also be paid to literacy issues in relation to the content of ISLEs, in other words, what about the 'science'? Scientific literacy is often described as the cornerstone of science education (Kelly, 2010). Conceptualisations of scientific literacy within the field of science education vary and are contested. Simply put, they range from perspectives that emphasise what Roberts (2007) has described as scientific knowledge, or content knowledge (the skills and information needed to be able to 'do' science) on the one hand, to, on the other, ideas that foreground socio-scientific literacy (the social, cultural, political or other contexts that science is involved with).

In ISLEs scientific content knowledge is frequently a prerequisite for making sense of an activity or exhibit. Tunnicliffe and Laterveer-de Beer's (2002) research, for example, shows that in order for visitors to use a hands-on interactive of replica skeletons to learn about zoology in a science museum they first had to know about how the skeletons of different kinds of animals worked. They concluded 'the knowledge of zoology amongst most visitors assumed by the exhibit designers was far higher than they possessed' (Tunnicliffe \& Laterveer-de Beer, 2002, p. 133), thus visitors who entered the museum without much zoological knowledge left this exhibit with little more.

Scientific literacy and museum literacy are not, however, the only forms of literacy needed by visitors to ISLEs. As Bain and Ellenbogen (2002) have argued visitors to ISLEs are faced with a need for multiple literacies. Not only do visitors need to understand how to navigate a science centre, zoo or museum to their own advantage (museum literacy), but they also need a range of content-based literacies. For example, in the case of a science museum a level of scientific literacy may be required, but beyond that visitors may also require background knowledge to understand the history or geography presented in the museum, not to mention other kinds of background knowledge that may be necessary (Bain \& Ellenbogen, 2002; Hooper-Greenhill, 1995; Schlereth, 1992).

Research also suggests that a more literal form of literacy is needed by ISE participants. Just as Norris and Phillips (2003) have argued that scientific literacy rests upon fundamental literacy (to be able to read and write), so too does ISE literacy. Research has demonstrated that visitors to ISLEs need to be able to speak and, almost more crucially, to be able to read the language of the institution, in order to understand not only the signage and opening hours, but also exhibit texts (Ash, 2004; Garibay, 2009; Yalowitz, Garibay, Renner, \& Plaza, 2013). While this may in some senses appear an obvious and taken-for-granted aspect of literacy and access issues, it emerged as a key problem for people from non-dominant ethnic and linguistic backgrounds who are less familiar with the dominant language when 
attempting to visit an ISLE (Ash, 2004; Tenenbaum \& Callanan, 2008) as well as within science classrooms (Shanahan, Pedretti, DeCoito, \& Baker, 2011).

ISE literacy can therefore be understood as plural, as a multifaceted issue, including aspects of museum literacy, scientific literacy and fundamental literacy, as well as other aspects of content literacy that may overlap with the science presented in ISE. Under this description of ISE 'literacies' achieving fluency is no mean feat given the different sets of knowledge and skills required and this highlights how important literacy issues are for understanding equity and access in relation to ISE.

\subsubsection{Literacy and inaccessibility in ISE practice}

A study carried out in London is a useful example for understanding the extent to which ISE literacy can limit access for some people. Research carried out with adults from four different minority ethnic, socio-economically disadvantaged community groups found participants struggled with ISE literacy on a number of fronts in ways that overlapped to create ISE experiences that were off-putting (Dawson, in press). The epistemic practices of the ISE institutions visited for the study relied on assumptions of English language fluency, scientific background knowledge and a series of specific learning behaviours, such as expecting participants to be able to understand how to use computer interactives, complex exhibit text or answer staff questions during facilitated workshops.

In literacy terms, the overlap of complicated and specific scientific language, such as 'cells', 'pH' or 'habitat' with English language, a language that despite being multilingual, participants were not fluent in, prevented participants from being able to access the information contained within science museums and science centres. Framing such literacies as forms of cultural capital, the study found that without pre-existing forms of cultural capital participants were unable to build or accrue additional capital through the ISLE visits. While participants were physically present within the ISLEs, they were unable to access the concepts or learning media they encountered (Dawson, in press). Following Bourdieu's theories of the reproduction of disadvantage presented earlier in Figure 1, the study found participants' encounters with ISE practice left them more disposed against participating in ISE than they had been before (Bourdieu \& Passeron, 1990).

Research in the USA suggests ISE literacies pose significant problems for 'new' or 'other' participants in ISE. Research with people from minority ethnic and minority linguistic backgrounds found they were uncomfortable with what they were expected to do within a science centre, museum or aquarium and confused about socially acceptable behaviours, exhibitions and exhibits; 'they often needed to do extra work to "figure out" what the exhibit "wants" them to do' (Ash \& Lombana, 2011 , p. 3). Research with Latino community members found ISE institutions were expected to be unfriendly places where visitors were expected to see but not touch, with difficult scientific content that was hard to understand (Garibay, 2009). Conversely, when their languages were represented, people from Spanish-speaking backgrounds in the USA felt more valued by the ISLE, more comfortable during their visits and felt the institutions were more culturally relevant (Yalowitz et al., 2013). These studies show the central role of ISE literacies in issues of access and equity; without addressing how to help and support 'non-typical' ISE participants access the content of ISE and better understand the 'rules of the game' initiatives that focus only on addressing infrastructure access may be limited. 
It may be particularly important that those involved in orientation to and mediation of ISE institutions or activities consider how to better support ISE literacies. The Viennese Knowledge Shops, for example, displayed the 'rules of the house' in different languages on the walls of the disused shops they took over to help visitors know what to do and how to do it (Streicher et al., 2014, p. 4). Research also suggests family mediation plays a crucial role in enabling people to enjoy and learn from ISLE visits (Ash, 2003; Ellenbogen, 2002; Palmquist \& Crowley, 2007). The central role of family mediation in visits to science centres, aquaria or museums suggests that providing more explicit and accessible support for families to build ISE literacies could be valuable. Similarly, while not all ISE participants interact with staff during visits to ISLEs, staff facilitation has been found to make or break a visit (Ash \& Lombana, 2011; Ruiz-Funes, 2008; Uyen Tran \& King, 2007). Thus, explicit staff facilitation on developing ISE literacies, not only through the mediation of science learning opportunities, but general orientation, language support and assistance with decoding exhibits, interactives and activities may be particularly valuable for disadvantaged or new participants.

\subsubsection{ISE literacies and power}

To understand how epistemic practices within ISE create such difficult conditions for people from disadvantaged social positions it is useful to turn again to theories from social justice and social reproduction. While Porter's (1998) use of literacy as a component of access is valuable, it is important to consider the implications of being 'illiterate' and the relationships between supposed literacy deficits and power. Based on a review of ISE practice in the USA Fenichel and Schweingruber (2010) concluded that for underrepresented groups, ISE posed particular problems since the science learning opportunities they encountered 'often privilege the science-related practices of middle-class whites and may fail to recognise the science-related practices associated with individuals from other groups' (p. 120). In this sense, the 'rules of the game' that non-dominant visitors are expected to be able to notice, understand and operate successfully within are, as suggested above, norms and expectations that may not be their own (Bourdieu \& Wacquant, 1992).

It is important, therefore, to go beyond positioning ISE literacies as composed of deficits on the part of 'non-visitors' and to consider, in addition, how differences in expectations, behaviours and cultural or social norms relate to power. As Young has argued, writ large, such differences can be understood as the difference in power between social groups:

Cultural imperialism involves the universalisation of a dominant group's experience and culture, and its establishment as the norm. Some groups have exclusive or primary access to what Fraser (1987) calls the means of interpretation and communication in a society. (Young, 1990, p. 58)

The power structures embedded in the epistemic practices of ISE, whether in terms of assumptions about fundamental literacy, scientific background knowledge, other content-based literacies or ways of learning, can be understood as dominant forms of interpretation and communication. From this perspective ISE literacies can be framed as an issue of power; whose knowledge matters, whose practices matter and, in the end, who matters. 
Examining gendered practices in ISE provides useful examples of the relationship between literacies and deficits. Research into gender equity in ISE carried out by Dancu (2010) at the Exploratorium, a science centre in the USA, found that exhibits were designed in ways that made the majority of them more popular with boys than with girls. She found exhibits that were off-putting to girls included, for example, those designed to be used by only one person at a time, with text lacking connections to people or the 'real world' and exhibits with little or no representation of females in text language, examples or images used (Dancu, 2010). Research suggests gender issues in science centres and science museums are compounded by the social interactions of visiting groups (Ramey-Gassert, 1996). For example, Crowley, Callanan, Tenenbaum, and Allen (2001), Crowley (1999) and Borun (1999) all found parental facilitation during science museum visits favoured developing science learning opportunities for boys at the expense of their sisters; parents talked more with boys about the science content of exhibits, asked them more questions and used more complicated language. The research suggested ISE institutions were places parents saw as more valuable for their sons than for their daughters (Borun, 1999).

Interpreting research on gender in ISE with a focus on ISE literacies suggests that not only were ISE exhibits designed in ways that were unappealing to girls limiting the science learning opportunities available to them - but that male-centric parental facilitation meant girls had fewer opportunities to develop the skills needed for scientific literacy or museum literacy. Under such circumstances I suggest it is important to turn the notion of literacy on its head. Girls were not ISE illiterate, but rather the norms, values and assumptions embedded in ISE exhibits and parental facilitation disempowered girls.

Similar patterns can be seen in how representations of science in ISE can create problems for people from non-dominant groups. Despite academic debates, within schools, curricula, textbooks, ISE institutions and ISE activities, science is predominantly represented as an authoritative body of knowledge that people are required to learn, rather than something relevant to their cultures, knowledges or interests (Calabrese Barton, Ermer, Burkett, \& Osborne, 2003). This is a problem because research suggests that narrow and authoritative representations of science privilege those amongst the already dominant social groups and alienate people from non-dominant social groups (Medin \& Bang, 2014; Roth \& Calabrese Barton, 2004; Shanahan \& Nieswandt, 2011).

As Pedretti (2002) suggests, however, challenging representations of science in ISE is far from straightforward. The interpretive hazards faced by making science public seem to produce representations of science that portray 'the canon' of scientific knowledge, leaning away from controversy or science as a fluid practice in-themaking, contingent upon social, cultural and/or political pressures. For example, Gieryn's (1998) account of the development of controversial science exhibitions at the Smithsonian Institute in the USA highlights a tendency for ISE institutions to be risk-averse and present the authority of scientific knowledge as a universal truth. Similarly, in studies of gender and sexuality in natural history exhibitions, Machin (2010) and Levin (2010a) found representations of sexuality that did not fit within a heteronormative frame simply disappeared. Elsewhere McNeil (2007) has shown that the ongoing portrayal of public science as the stories of heroic White, upperclass men reifies Newton, Faraday and Darwin at the costs of more open, inclusive and ordinary accounts of science and scientists. As Macdonald's (2002) ethnographic study of exhibition development at the Science Museum in London attests, 
ultimately epistemic practices in the museum resulted in authoritative representations of science.

Representing science appears to be difficult, therefore, for ISE in ways that render an authoritative representation of science as the established norm. Drawing on Young (1990, 2000), such representations can be understood as a form of cultural power. As Gieryn argues, science museums contend with science as a series of 'little truths whose legitimacy rests not on reality but on normatively enforced standards of evidence, argument and purpose' (1998, p. 197). Thus for people from non-dominant social groups, learning 'authoritative' science requires the negotiation of two sets of practices or literacies: those associated with science and those of the dominant culture, both of which may be off-putting (Aikenhead, 2002; Medin \& Bang, 2014). In this sense developing ISE literacies such that a person knows the 'rules of the game' can be understood as more difficult for some people than others. In other words, the 'game' is rigged.

As argued earlier, educational institutions, including ISE institutions, have been understood to reinforce the advantages of the advantaged by operating within the 'culture of power' (Delpit, 1988, p. 282). Thus a critical reading of research on ISE literacies suggests certain participants are not 'illiterate' but rather that they encounter situations in which they are disadvantaged by the embedded assumptions of ISE and the 'culture of power' therein (Bourdieu \& Darbel, 1991; Macdonald, 1998; Rice, 1992). While the notion of ISE literacies provides a useful way to frame issues of conceptual access and equity in ISE, it is important to take a critical approach to the implicit notions of deficit and illiteracy. Deficit orientations work to privilege certain forms of knowledge and practice over others and in doing so privilege the groups with access to those forms of knowledge and practice over those without that access (Yosso, 2005; Young, 1990). Thus I suggest taking a critical perspective on the roles of power within ISE literacies enables ISE researchers and practitioners to acknowledge the need for both a redistribution of such literacies alongside a recognition of different forms of literacy, knowledges and practices (Fraser, 2003; Young, 1990, 2000).

\subsubsection{Reframing ISE literacies: A critical pedagogy approach to difference and power}

What does it take to be able to negotiate, navigate, manage and even benefit from the science learning and engagement opportunities of ISE? The literature on educational equity and learning suggests there are two key strategies relevant for addressing equity and access within ISE literacies as outlined above. Firstly, work from sociocultural constructivist pedagogy as developed by Vygotsky (1978, 1986), Bruner (1966) and Wertsch (1985) can be used to understand the concept of difference and how difference can be addressed within the literacies elements of science learning in ISE. Secondly, drawing on concepts developed by Freire (1998), Freire and Freire (1992), hooks (1994) and Delpit (1988, 2006) from critical pedagogy, it is important to understand how power disparities might be addressed in science learning and ISE literacies.

Addressing the issue of how learners, visitors or participants differ and the influence of those differences is a key issue for understanding how the concept of ISE literacies can be used to improve equity and access. Just as research from sociocultural studies of science education suggests that who you are changes your 
experience of learning science (Lemke, 1990; Shanahan \& Nieswandt, 2011; Tan, Calabrese Barton, Gutiérrez, \& Turner, 2012), so too research on cultural participation suggests that prior experiences, attitudes, knowledges and expectations influence whether you would visit a museum in the first place (Bourdieu \& Darbel, 1991; Hooper-Greenhill, 1994). Understanding people's backgrounds, knowledges, cultures and taking them into account could therefore be key to developing more inclusive ISE practices.

The notion of 'cultural humility' developed in multicultural medical education is a useful conceptual tool here for ISE researchers and practitioners (Tervalon \& Murray-Garcia, 1998). Tervalon and Murray-Garcia (1998) argued that practitioners (in their case medical professionals) ought to develop a sense of cultural humility working with diverse populations through reflection, critique and collaboration, rather than a more narrow sense of cultural competence, which they suggest is not only difficult to truly achieve but potentially patronising and off-putting. In other words, rather than trying to second guess and define a range of diverse cultures (for example, assuming hair braiding workshops in science museums will appeal to African-Caribbean communities, which may draw in some visitors, remains a narrow way to represent such communities and their cultures) ISE practitioners may be better able to respect and represent diverse communities through working in collaboration and fostering a sense of cultural humility in their work. Thus, taking 'difference' into account need not require ISE practitioners to single-handedly understand the millions of specific and different backgrounds people bring with them, but rather to be able to recognise and respect differences and foster collaborations that provide them with the support, perspectives and experiences needed to develop inclusive ISE opportunities.

At the level of pedagogic theory, sociocultural constructivism provides a conceptual framework within which individual and group differences can be understood in relation to learning. Simply put, everyone learns differently in ways that are influenced by both their prior experiences and expectations as well as the learning environment (Wertsch, 1985). Such a model enables 'difference' to be included in understanding how learning does and does not happen and can help those working in and researching designed learning environments such as ISLEs to account for difference both analytically and in practice. Recognising and working with difference may be a key aspect of developing more equitable, more accessible forms of ISE practice and broadening ISE literacies to help make space for more people, more practices and a greater diversity of 'ways in' to science.

Sociocultural constructivist pedagogy as developed by Vygotsky (1978, 1986), Bruner $(1960,1966)$ and Wertsch $(1985)$ is particularly useful for understanding the roles of social position in learning since learning (and teaching) are seen as nested within social and cultural contexts. For Vygotsky, therefore, learning resulted from 'the sociocultural experience of the child' (1986, p. 94). Because learning uses the building blocks of previous experiences - since as Bruner put it 'knowing is a process, not a product' (1966, p. 72) - each learner brings something different with them to each learning experience. Importantly, such perspectives position all learners as different, not just those from certain social groups or backgrounds.

A sociocultural constructivist approach to pedagogy suggests, therefore, that taking the backgrounds of all learners into account is a key part of how ISE could support more equitable and more accessible science learning opportunities and open up what forms of knowledge are useful for ISE literacies. For example, researchers 
have explored developing culturally relevant science learning opportunities based on the knowledge systems of non-dominant groups and, as a result, reframing Western science (Medin \& Bang, 2014; Stanley \& Brickhouse, 2001). Drawing on these ideas researchers developed notions of alternative, critical or multicultural science literacy (Basu, Calabrese Barton, \& Tan, 2011; Tan et al., 2012). For example, the concept of 'critical science literacy' (Basu et al., 2011, p. 117) suggests that scientific content knowledge, socio-scientific issues and community knowledge are important facets of learning science in a relevant and meaningful manner, in a way that is similar to the idea of cultural humility. Thus, changing who is represented, whose stories are told and/or whose languages are used in exhibits or programmes could significantly open up ISE literacies.

Bruner (1966) also argued that not only do the social and cultural backgrounds of learners matter, but the smaller interactions of teaching (whether the teacher is a parent, peer, classroom teacher or ISE 'explainer') leave social and cultural traces upon the learning at hand. For example, the research on gendered experiences in science centres described above suggests the social and cultural shadows left by interactive science exhibits may be different for girls than for boys, reinforcing social norms that link masculinity and science (Crowley et al., 2001; Dancu, 2010; Ramey-Gassert, 1996). Similarly, as Aikenhead (2006) has argued, some people have to do more work to move between their own cultural backgrounds and those of science learning, while for others such 'border crossing' practices are barely needed. Thus the perspective described by Rahm (2010) is useful here since, following Vygotsky and Wertsch amongst others, she has described learning as a process of becoming and of identity work, situated in complex historic, cultural, social and political contexts. As a result, therefore, I suggest that the presence of these social and cultural traces means that explicitly acknowledging and addressing questions of power within ISE literacies could provide people with tools to understand why some of these differences exist and are reproduced, as well as the tools to begin to disrupt such processes.

The value of taking a critical pedagogy perspective to explicitly include power as a feature of ISE literacies is that it opens the door for critically reflecting on the assumptions, norms, expectations and power practices embedded within ISE (Freire, 1998; hooks, 1994). By drawing on critical pedagogy I suggest the problems of a deficit orientation in ISE literacies become clearer (people are not illiterate, they are disempowered) and, at the same time, the need to open up ISE literacies can be understood as a way to empower more people, to disrupt rather than reproduce cycles of social disadvantage.

Certain forms of knowledge and certain social groups are privileged in societies and without acknowledging the roles of power in such practices, it is hard to 'offer strategies for social transformation' (Yosso, 2005, p. 71). Thus from a critical perspective, equity and access are crucial features of ISE literacies, since by making the norms for interaction in ISE explicit (Delpit, 1988), including the roles or power, the implicit, coded and semi-secret behaviours required for successful participation in ISE and the resources they represent could be opened up to more people. As Brice Heath (2007) has argued, developing environments where ISE literacies are explicit and that allow the different elements of such literacy to be explained, modelled and developed, is crucial for inclusion and access not just in ISE, but within broader aspects of science, such as opening up STEM subjects and STEM careers. A critical pedagogy of ISE literacies therefore has three steps: firstly, recognising that multiple 
forms of literacy are needed for participating successfully in ISE; secondly, acknowledging and making explicit the role of power; and thirdly, reframing ISE literacies to include the knowledges, skills and practices of 'different' and 'other' groups amidst the canon of authoritative science content.

\subsection{Community acceptance}

The last element of Porter's (1998) tripartite access framework is concerned with community acceptance; the need for a community of users to accept those formerly excluded. As developed by Grabill (1998) community acceptance can be understood as the extent to which practitioners in a particular learning environment are willing to critically reflect upon and potentially redevelop a given learning environment to better accommodate more people, for example, in terms of gender issues, 'race'/ethnicity, class or sexuality. ISE community acceptance might therefore include ISE staff drawing on critical pedagogy to examine how particular science learning opportunities, such as individual exhibits or interactives, limit the potential for certain visitors to engage with science.

The concept of community acceptance also implies that ISE practitioners would build on critical reflection through changing practices, such as redesigning a computer-based interactive exhibit, to become more accessible. Community acceptance specifically focuses on how previously excluded groups might be made to feel welcome. Thus, as well as designing more accessible science learning opportunities, it may also be important to think about using a broader range of languages, providing affordable food and souvenir shops (Dawson, in press). Porter (1998) and Grabill (1998) suggest such shifts in practice are key to realising and sustaining accessibility.

\subsubsection{Community acceptance as a challenge for ISE}

Embracing the notion of community acceptance is no mean feat. The notion of community acceptance as described by Porter (1998) and Grabill (1998) would require ISE institutions and their representatives to take responsibility for exclusive practices and to address problematic aspects of ISE infrastructure access and ISE literacies. The changes implied by ISE community acceptance may come with costs, however, not least the resources needed to significantly reorganise current practices. Creating the change required to address inequity and inaccessibility in ISE, while difficult, may nonetheless be a crucial step towards ISE becoming more inclusive. Changes become necessary because, as Young has argued, 'bringing about justice where there is exploitation requires reorganisation of institutions and practices in decision-making, alteration of the division of labour, and similar measures of institutional, structural, and cultural change' (1990, p. 53). From this perspective, the assimilationist approach, outlined at the start of this article, can be understood as a seemingly easier, albeit ultimately more problematic, way for institutions to address equity, since it requires relatively little change on the part of ISE.

Assimilationist approaches to equity and access in ISE rest on the assumption that infrastructure access alone is the underlying problem for ISE equity and accessibility (Fenichel \& Schweingruber, 2010). Thus, as Lee (1999) has argued, assimilationist practices require no revision of existing ways of representing science or people, nor do they require critical reflection on ISE practices, such as infrastructure 
access or ISE literacies, or the transformations that might be needed to take difference into account (Bell et al., 2009; Fenichel \& Schweingruber, 2010). An assimilationist approach enables ISE researchers and practitioners to position equity and inclusion as problems that arise from the behavioural or knowledge-based deficiencies of those who do not participate (Bell et al., 2009).

As with other practices involved in making science public, imagining potential publics provides ISE practitioners with a mechanism for pitching their practices (Litt, 2012; Matthews, 2008) and for framing participation (and non-participation). The problem with these projections of 'typical visitors' and 'non-visitors' lies in how such imagined constructs subtly and less subtly influence ISE design processes and decisions. ISE practitioners use imagined visitors to develop exhibits, select the objects and images to be used, to write exhibit texts for, titles, select price points and more (Macdonald, 2002).

Research suggests these imagined publics are limited, in ways that mirror the socially narrow participant profile of ISE. For example, research in the UK identified these imagined, prospective visitors as scientifically literate, middle class, White and either part of a small family group or a school group (Dawson, in press). Thus, by drawing on a limited conceptualisation of who ISE participants 'could' be, ISE practices become embedded with assumptions about literacies, infrastructure accessibility and 'who' counts as a visitor. Re-imagining who ISE participants could be, while far from simple, may be a key aspect of ISE community acceptance of difference and inclusion.

To understand ISE community acceptance as distinct from an assimilationist approach, it is important to think about the different aspects of recognition of difference and redistribution of resources that may be required to engender inclusive ISE practices and to think about what they might look like in practice (Fraser, 2003; Young, 1990). For instance, one element of ISE community acceptance could include re-imagining visitors by diversifying ISE staff recruitment and development. The 'Career Ladder' programme developed by the New York Hall of Science is a long-term staff recruitment programme designed to both diversify the ISE staff by mirroring the demographics of the local area within the workforce and to provide tangible STEM career opportunities and resources for participants in the programme (New York Hall of Science, 2010).

The programme was found to meet the needs of the 'Explainer' participants in terms of their career development and personal goals (Storksdieck, Haley-Goldman, \& Jones, 2002). Notably, as 'Explainers' move through the programme they became paid members of staff, rather than volunteers, thus closer to Lynch's (2011) criteria for core rather than peripheral participation. The example of the New York Hall of Science 'Career Ladder' demonstrates that some ISE institutions have developed practices that break the mould in terms of equity and inclusion; such examples appear, however, to be relatively rare within the literature. What the New York Hall of Science example demonstrates is that it is possible for ISE practitioners and institutions to re-imagine who their visitors and staff might be and develop a sense of community acceptance towards 'new' or 'different' participants.

\subsubsection{Community acceptance as part of a complex system}

Porter (1998) and Grabill (1998) used community acceptance to refer to acceptance by those already in a given practice community of those who were formerly 
excluded, as illustrated by the example of the New York Hall of Science above. Bourdieu's work suggests a more complex approach to community acceptance might be useful for understanding access, equity and inclusion in ISE. Drawing on Bourdieu (1977) and Bourdieu and Wacquant (1992), I suggest community acceptance can be read in multiple directions, to mean not only recognition, acceptance and welcome on the part of those already in the ISE community but also recognition, acceptance and perceived relevance on the part of those 'excluded' communities that ISE is worth their time and effort. In other words, community acceptance cuts both ways.

Garibay's (2009) research, for instance, suggests that for second-generation Latinos in the USA, without representation of their own culture, own language and own interests, ISE was perceived as irrelevant and 'not for us'. In French-speaking Canada, marginalised students struggled to see ISE programmes as relevant to their lives (Rahm, 2008). Similarly, in the UK, research into the attitudes of minority ethnic groups towards museums in general found such places were seen as unappealing and unconnected to their lives (Tissier \& Singh Nathoo, 2004), while research specifically about ISE mirrored these findings (Dawson, in press). From this perspective, drawing on ideas about the reproduction of social disadvantages developed by Bourdieu (1977) and Bourdieu and Passeron (1990), the attitudes, behaviours and habitus of those who do and do not participate in ISE can be understood as a key part of the system. Put another way, community acceptance requires communities who view ISE as irrelevant to their lives to shift their dispositions towards, rather than away from ISE, without which patterns of participation in ISE are unlikely to change, and may hinge on changes to infrastructure access and ISE literacies leading the way.

The San Jose Children's Discovery Museum in the USA provides a useful example of how ISE might redevelop practices to address concerns about equity and inclusion. The museum redeveloped much of its practice by working in collaboration with the local Vietnamese community (Fenichel \& Schweingruber, 2010). The Children's Discovery Museum sought to build long-term, mutually beneficial relationships with the San Jose Vietnamese community through understanding what put them off visiting the museum - for example, the economic costs of visiting, such as entry fees, parking, transport, language difficulties, no Vietnamese staff and negative expectations of museums - and trying to address these issues. In thinking about what cultural humility might mean for ISLEs, collaborative projects of this type may be invaluable opportunities for reframing ISE opportunities in ways that are more accessible and inclusive.

Following the initial development phase, museum staff and Vietnamese community members worked together to create an exhibit that would combine scientific and mathematical content with artefacts and stories that were relevant to the Vietnamese community and exhibit interpretation with Vietnamese translations. While the research suggests the project was far from straightforward, working in partnership with community members was found to create a more inclusive science and math learning experience for visitors, create opportunities for staff to critically reflect on their work and meet at least some of the needs of the Vietnamese community (Fenichel \& Schweingruber, 2010). This example suggests that changes on both sides of community acceptance require financial investment, time and commitment from all parties. Notably, the institutional side of community acceptance was a necessary first step in the process and in doing so worked towards reimagining their 
visitors, by developing a concrete sense of these visitors' needs and relevance, through which the visitor profile of the institution ultimately shifted.

A second useful example comes from work carried out by the Parque Explora science centre in Medellin, Colombia, with communities that are arguably very vulnerable. Parque Explora worked in collaboration with local communities from the densely inhabited Moravia neighbourhood which developed on top of the "municipal dump' (Aguirre, 2014, p. 3). The science centre also worked alongside the local environmental control agency and local government to develop projects that sought to build long-term relationships between these different stakeholders and address housing issues, environmental problems and social inclusion against a background of significant social injustice.

As with the previous example, themes that stand out in relation to community acceptance include the long-term approach to developing relationships that serve community needs, a significant commitment of resources and collaborative ways of working. Notably, the projects devolved power from the larger institutions to community leaders, their networks and trained community members to develop scientific skills and facilitation skills, which ultimately resulted in a significant level of community participation. Aguirre (2014) acknowledges, however, that even in ambitious projects such as these, ISE institutions and practitioners need to recognise their limits, and advocates working directly with other organisations that can address social problems and needs that may be outside an ISLE's remit. Nonetheless, in the short term at least, the work of Parque Explora appeared to shift the relationships between the science centre and the Moravia community, empowering that community by making the science content involved in the environmental issues they face understandable and relevant, developing a sense of community acceptance on the part of all stakeholders.

Community acceptance is therefore a multifaceted concept. I suggest, drawing on Porter (1998), Young (1990), Fraser (2003) and Bourdieu (1990), that community acceptance requires ISE institutions and their representatives to take responsibility for implementing changes that could lead towards more inclusive, more accessible ISE. The steps involved in such a process could include changes to ISE infrastructure and literacy practices that acknowledge, respect and represent difference, create more ways for more people to access ISE and reflect critically on the role of power in practice. It is, however, also important to recognise that community acceptance on the part of the excluded, potential audiences is also required. In other words, that those from non-dominant groups who are currently not represented amongst ISE audience figures would need to find ISE relevant, interesting and inclusive in order to want to participate. This element of community acceptance can, however, be understood as a second phase, since without community acceptance on the part of ISE institutions and practitioners, their policies, practices and staff, it would seem unlikely that 'non-visitors' would change their attitudes and behaviours.

\section{Conclusion and implications: developing an equity framework for ISE}

At the start of this article I argued that finding ways to understand and address the issues of inequity and inaccessibility was a key challenge for research and practice in ISE. The evidence reviewed here on who does and does not participate in ISE suggests that ISE can be understood as only partially public, with participation marked by social advantage and disadvantage in ways that are not accounted for by 
an assimilationist approach to inclusion. Notably, however, questions of equity have received less research attention in ISE than in 'formal' science education.

This article demonstrated that Porter's (1998) access framework, developed for understanding community computer literacy, can be usefully applied to ISE and that the concepts of infrastructure access, literacy and community acceptance provide a valuable way to begin to examine access and equity in ISE in ways that go beyond an assimilationist approach. Thus, Porter's (1998) framework provides a useful set of building blocks for those interested in developing more inclusive ISE practices to start a process of critical reflection, evaluation and development.

While useful, applying Porter's (1998) framework to ISE was limited in certain ways, for example, in the extent to which deficit orientations were challenged and how power was addressed in the specific context of ISE. I augmented the access framework by drawing on theoretical perspectives from work on social justice (Fraser, 2003; Young, 1990, 2000), sociology of disadvantage (Bourdieu \& Darbel, 1991; Bourdieu \& Johnson, 1993; Bourdieu \& Passeron, 1990) and learning (Bruner, 1966; Freire, 1998; hooks, 1994; Wertsch, 1985) as well as empirical research, to outline a theoretical framework for understanding access and equity in the context of ISE. The argument outlined in this article extends, therefore, the approaches to inclusive practice in ISE advocated by Bell et al. (2009) and Fenichel and Schweingruber (2010) by drawing on international research and theoretical perspectives from outside education studies.

The key conclusion of this article is that ISE access, equity and inclusion/exclusion ought to be understood as complex, interconnected and multifaceted issues. I have argued that inclusion in and exclusion from ISE are embedded, resilient and multidimensional, influenced by ISE practices, the communities of practitioners, visitors and 'non-visitors' as well as the broader society. As such, quick fixes and simple solutions are limited in the extent to which they are able to address the complicated nature of access and equity in ISE. While such conclusions are not intended to suggest that practitioners, policy-makers or researchers involved with ISE should give up on access projects, I argue that understanding inclusion and exclusion from ISE as complex suggests that developing inclusive ISE practices requires careful attention, resources and a significant commitment.

By placing concerns about social justice and the role of ISE in the reproduction of social disadvantage at the heart of an access and equity framework for ISE, this article has sought to outline a critical pedagogy approach for ISE. In applying Porter's (1998) access framework to ISE I have shown that each aspect of that framework - infrastructure access, literacy and community acceptance - needs to be understood in relation to one another, as components of a wider framework for access, equity and inclusion. As a result addressing only infrastructure access or only literacy is not sufficient for developing inclusive ISE. Moreover, concerns about redistribution, recognition, representation and power run through all three of these key issues. Thus the framework for access, equity and inclusion in ISE developed here brings together concerns about access and redistribution, recognition and power to develop ways to critically reflect upon and develop ISE. The framework in Table 1 below is an attempt to outline some of the components involved in thinking about equity in ISE.

It is important, however, to note that any model or framework suffers from limitations. In this case, for example, social and cultural norms are fluid and depend on their context, thus what may be the case for one country may not apply elsewhere; 
Table 1. A framework for access, equity and inclusion in ISE.

Key issues

1. ISE infrastructure Recognition of uneven ISE infrastructure access and what that might access look like in a specific context.

Redistribution of access to ISE opportunities.

Recognition that redistribution entails changes to ISE practice.

Recognition and respect for 'difference' to create meaningful and relevant ISE opportunities for a diverse range of people.

2. ISE literacies Recognition of ISE literacies as multiple, including 'museum' literacy, 'scientific' literacy, 'fundamental' literacy, a range of 'content' literacies and an awareness of the role of power.

Make the 'rules of the game' or ISE literacies explicit.

Open up the 'rules of the game' to include a more diverse, more inclusive set of knowledges, practices and people.

Recognise, respect and represent diversity in ISE content, staff, target audiences, marketing strategies and so on.

3. Community Recognition that the ISE community needs to accept and welcome acceptance 'new' audiences, making changes to practice, such as ISE infrastructure access and ISE literacies as appropriate.

Recognition that community acceptance is multifaceted and multidirectional.

Commitment to access, equity and inclusion in ISE.

Acknowledge changes in ISE practice need to precede changes in patterns of participation.

similarly, how such a framework may apply in practice to a particular ISE institution, activity or community of 'non-visitors' will be context specific. Although this review has drawn on a range of international research, it is important to note the complex, highly contextual nature of equity and access issues, which implies a degree of caution is necessary in outlining a precise list of practical action points. Developing an equity and access framework for ISE based on theoretical concepts as well as empirical data is, however, important because at the moment the field lacks the conceptual tools to understand and address the processes of exclusion. For researchers and practitioners interested in ISE this article attempts to provide a theoretical position from which to develop critique, reflection, empirical research and practice.

While it is important to simply develop a better, more useful way to understand inaccessibility and inequity in ISE, in drawing on theories of social justice and critical pedagogy I suggest it is equally important to use that understanding to reframe ISE as a more inclusive field of practice, with research that supports such developments. In what follows I draw on the theoretical framework developed in this article to outline some implications for creating more inclusive ISE practices and implications for research that will hopefully provide starting points for discussion, reflection, critique and development.

\subsection{Implications for practice}

Developing a definitive set of guidelines and implications for accessible and inclusive ISE practice based on the research reviewed here is a difficult task, though an 
important one for research on ISE. This review has focused on how to understand and think about access and equity, exploring issues in practice where possible in order to try and ground conceptual arguments in examples of real ISE activities. A key theme developed in this paper is that access and equity issues are highly complex and context specific, entrenched within local histories (institutional and community-based) as well as global histories. As a result, as Table 1 demonstrates, I have been cautious about trying to pull out 'what works, where and when' from examples of ISE practice described here. Instead, I have sought to develop a conceptual framework that could support ISE researchers, practitioners, funders and policy-makers thinking about, discussing and potentially changing practices across a range of contexts.

While the elements of the ISE access and equity framework developed in this article are not a proscriptive list of ingredients, some tentative implications for practice can be drawn from them. Notably, these implications may be applicable beyond the particular context of ISE, for example, they may be relevant for informal science learning beyond institutional contexts, the broader field of science communication and public engagement with science as well as museums, galleries, festivals or other learning spaces that are not based on science content. Given the themes of cultural humility, recognition and respect for difference and relational social justice developed in this paper, the implications I outline here do not focus on claims about how best to work with specific groups (e.g. tips about how to design exhibits for London's Polish community, which are beyond the scope of this review), but rather suggest potential shifts in practice that could be useful.

The over-arching implication of this article is that the problems of inaccessibility and inequity need to be taken seriously and, concurrently, that those involved in ISE practice, policy and research ought to take responsibility for developing more inclusive practices where possible. Doubtless, an implication of this kind is difficult to imagine, let alone realise in practice, because of the complicated and multiple nature of possible changes. Specific changes to practice can, however, be pointed towards as a starting point for thinking about action on a case-by-case basis.

This article suggests, for example, that taking ISE literacies seriously is an important leverage point for access and equity. As others have argued, accessible and fair learning opportunities hinge upon the 'rules of the game' being made clear (Bourdieu, 1990; Brice Heath, 2007; Delpit, 1988). To this I would also add a need to rethink some of these 'rules', to make them more flexible and to create learning opportunities that allow more 'ways in', drawing, for example, on notions of border crossing, hybrid and cross-cultural learning opportunities (Aikenhead, 1996, 2002; Roth, 2008). Putting such concepts into practice might include redesigning exhibits such that implicitly encoded forms of engagement are made explicit through clear instructions about how to make sense of an interactive or object. From this perspective, orientation and mediation, whether through artefacts, texts or staff facilitation, are key factors for supporting ISE literacy.

It would be valuable to experiment with decoding assumed scientific content knowledge, user guides about behaviours and norms, additional staff facilitation as well as literal translations into multiple languages. Additional languages could be included through text panels - as the Oakland Museum of California has done in the USA or as the Experimentarium Science Centre in Copenhagen has done in Denmark - through new technologies or through multilingual facilitation, which was 
found to be particularly effective at the Monterey Bay Aquarium in the USA (Ash, 2004).

This article suggests that working with and respecting difference in terms of people's social, cultural and linguistic backgrounds offers many opportunities for developing inclusive ISE practices. Such practices could include the literal representation of different kinds of people in imagery, objects, texts and stories, whether in terms of gender, as suggested by Dancu (2010), ethnicity and language (Garibay, 2009; Yalowitz et al., 2013), class or other social positions (see e.g. Levin, 2010b; Sandell, 2007; Sandell, Dodd, \& Garland-Thomson, 2010). Representation of difference could also include paying attention to the languages used within an institution, the forms of knowledge that are acknowledged as valuable and the recruitment of staff and volunteers.

As Porter's (1998) concept of infrastructure access suggests, such changes may be brought about through the inclusion of new and different voices into the design and decision-making processes of institutions. The potential influence of such changes to institutional cultural humility, process and content on community acceptance can be seen in the example of the San Jose Children's Museum described earlier (Fenichel \& Schweingruber, 2010), which suggests taking representation and difference seriously is important for ISE access and equity. Happily, sociocultural constructivist approaches to learning and teaching argue that taking difference into account is not impossible if considered, for example, at the point of curriculum design (or exhibit design) or in staff training (Bruner, 1966). In ISE terms this might include, for example, as suggested above, creating exhibits with more 'ways in', including representations of a wider range of people and considering different forms of staff mediation as well as how to support mediation within a range of differently shaped family groups.

The practice-based implications of this article also include larger questions about how changes in the behaviours and attitudes of ISE practitioners, institutions, visitors and 'non-visitors' can be developed in ways that are sustainable in the longer term. While I have argued that developing inclusive informal science involves a complex range of issues, this represents significant challenges for understanding, questioning and changing ISE. For example, this article cannot offer a conclusive answer to the problem of shifting from small or one-off 'inclusion' projects to the kind of field-wide institutional change that would make such projects unnecessary.

\subsection{Implications for research}

A key implication of this review for researchers is simply that we lack sufficient theoretical or empirical research on the questions involved in ISE access and equity. As I argued at the start of this article, while there is a growing literature on the benefits afforded to existing participants in ISE, there is remarkably little on the different issues involved in inclusion, exclusion and disadvantage in ISE. Pursuing further research is important not only to elaborate empirically upon the many issues involved in developing more inclusive practices, whether for informal science learning, communication or education, but also to continue to develop theoretical perspectives that can help to inform both the empirical research and practice.

The review carried out in this article raises several questions for researchers interested not only in ISE and the institutions, practitioners, practices and policies therein, but also in informal science learning and science communication more 
broadly. These include descriptive questions about access and equity (what are experiences of exclusion and inclusion in ISE like), questions about developing practice (how might ISE experiences be supported for more people) and theoretical questions about inclusive ISE and the roles of power in science education, learning and communication. For example, intersectional issues remain underexplored empirically and under-theorised; how do people who inhabit overlapping positions of disadvantage perceive ISE and what could be done to create empowering, respectful and sustained ISE opportunities for them?

Doubtless, exemplary inclusive ISE practices exist without making their way into the literature, which can only ever be a partial reflection of practice; however, more examples of research about practices that explore potentially inclusive activities within ISE are needed. Without developing the examples in formats that can be shared, built upon, critiqued, borrowed and re-made, field-wide changes to access and equity in ISE will remain elusive. Similarly, without developing theoretical perspectives that can be applied to underpin how inclusion in and exclusion from ISE are understood, framing research and practice on these issues will be limited. As such, I suggest it is important for researchers interested in ISE to consider the challenges posed by equity as a key area for research.

\section{Concluding comments}

ISE has vast potential for disrupting the reproduction of social disadvantages rather than reproducing them. In placing concepts of social justice, critical pedagogy and empowerment at the heart of ISE the affordances and benefits of participation in ISE may become more available to more people. I have argued that it is important to recognise how, where, when and for whom ISE practices reproduce social disadvantages by being inaccessible and/or inequitable. By doing so ISE policies, practitioners and researchers can begin to acknowledge where change is needed, to explore how to make those changes and, through developing more inclusive practices, may be able to shift community acceptance on the part of 'non-visitors' and, ultimately, change the current patterns of infrastructure access. While I recognise that an element of idealism is inherent in such work, I suggest striving for equity in ISE is of crucial importance to the field and I hope that this article may stimulate further discussion.

\section{Acknowledgements}

Special thanks to the staff of the Department of Science Education at the University of Copenhagen whom I visited with the ESERA Travel Award, for helpful comments on earlier drafts of this paper, not least Lars Ulriksen, Henriette Tolstrup Holmegaard and Marianne Foss Achiam for their feedback about deficit issues in science education. Further thanks to Jeff Grabill for feedback on an entirely different paper that instead influenced this one. I also thank Justin Dillon, Jonathan Osborne and Anwar Tlili for feedback on aspects of this paper that appeared in my $\mathrm{PhD}$ thesis, as well as Louise Archer and two anonymous reviewers for their useful comments on this manuscript.

\section{Funding}

The work that has gone into this paper has been supported by two separate grants, one from the UK's Economic and Social Research Council (ESRC) (award reference: ES/G018448/1) 
and an Early Career Researcher Travel Award from the European Science Education Research Association (ESERA), for which I am very grateful.

\section{Notes}

1. The 2011 version of the survey has an almost identical list of activities but notably did not include nature reserves as a category of science-related activities (Ipsos MORI, 2011, 2014).

2. Currently known as the Association for Science and Discovery Centres (ASDC), formerly Ecsite-UK and still part of the larger Ecsite network of European science centres and museums.

3. In their report on museum and gallery visitors, Ipsos MORI (2006) specify this as people from the AB social class, which relates to higher socio-economic positions according to this method of categorisation.

4. ISI Web of Knowledge and CSA Illumina.

5. These 'base' search terms were combined with 19 other terms, such as 'science centre', 'television' and 'internet' to ensure that all articles related to informal science learning were covered; the 'base' terms were also combined with 'science communication'. The search results were also compared with references from other review articles and books for the same reason.

6. These countries in order of number of publications were Israel, Taiwan, Brazil, Germany, Sweden, Greece, Norway, Italy, Spain, South Africa, Portugal, Switzerland, New Zealand, Mexico, Japan, Finland, Slovenia, Singapore and Serbia.

7. This example comes from my experiences as an ISE practitioner.

8. This example is drawn from field work and photographs on a research trip to South Africa.

\section{Notes on contributor}

Emily Dawson completed her $\mathrm{PhD}$ at King's College London, after which she carried out postdoctoral work and a lectureship there. She is currently a lecturer in Science Communication at University College London. She has been a practitioner and researcher in Science Communication and Science Education since 2005, working in museums and community heritage centres. Her research explores how social exclusion and inclusion operate within informal science learning practices and how people negotiate encounters with the science in their lives.

\section{References}

Aguirre, C. (2014). Science centers. Which roles can they play to participate in a city social reconstruction? Journal of Science Communication, 13(2), 1-12.

Aikenhead, G. (1996). Science education: Border crossing into the subculture of science. Studies in Science Education, 27(1), 1-52.

Aikenhead, G. (2002). Science communication with the public: A cross-cultural event. In W.-M. Roth \& J. Désautels (Eds.), Science education as/for sociopolitical action (pp. 151-166). New York, NY: Peter Lang.

Aikenhead, G. (2006). Science education for everyday life: Evidence based practice. New York, NY: Teachers College Press.

Ash, D. (2003). Dialogic inquiry in life science conversations of family groups in a museum. Journal of Research in Science Teaching, 40, 138-162. doi:10.1002/tea.10069

Ash, D. (2004). Reflective scientific sense-making dialogue in two languages: The science in the dialogue and the dialogue in the science. Science \& Education, 88, 855-884.

Ash, D., \& Lombana, J. (2011, April 3-6). Reculturing museums: Scaffolding towards equitable mediation in informal settings. Paper presented at the National Association for Research in Science Teaching international conference, Orlando, FL. 
Association of Science and Technology Centres. (1987). Natural partners: How science centres and community groups can team up to increase scientific literacy. Washington, DC: Author.

Atkinson, R., Siddall, K., \& Mason, C. (2014). Experiments in engagement: Engaging with young people from disadvantaged backgrounds. London: Wellcome Trust.

Bain, R., \& Ellenbogen, K. M. (2002). Placing objects within disciplinary perspectives: Examples from history and science. In S. G. Paris (Ed.), Perspectives on object-centered learning in museums (pp. 140-155). Mahwah, NJ: Lawrence Erlbaum Associates.

Bamberger, Y., \& Tal, T. (2008). An experience for the lifelong journey: The long-term effect of a class visit to a science center. Visitor Studies, 11, 198-212.

Bandelli, A., \& Konijn, E. A. (2012). Science centers and public participation: Methods, strategies, and barriers. Science Communication, 35, 419-448.

Bandelli, A., Konijn, E. A., \& Willems, J. W. (2009). The need for public participation in the governance of science centers. Museum Management and Curatorship, 24, 89-104.

Basu, S. J., Calabrese Barton, A., \& Tan, E. (2011). Democratic science teaching: Building the expertise to empower low-income minority youth in science. Rotterdam: Sense.

Bell, P., Lewenstein, B., Shouse, A. W., \& Feder, M. A. (2009). Learning science in informal environments: People, places, and pursuits. Washington, DC: National Academies Press.

Bennett, T., Savage, M., Silva, E., Warde, A., Gayo-Cal, M., \& Wright, D. (2009). Culture, class, distinction. Abingdon: Routledge.

Borun, M. (1999). Gender roles in science museum learning. Visitor Studies Today! 3(3), $11-14$.

Bourdieu, P. (1977). Outline of a theory of practice (R. Nice, Trans.). Cambridge: Cambridge University Press.

Bourdieu, P. (1984). Distinction: A social critique of the judgement of taste (R. Nice, Trans.). London: Routledge and Kegan Paul.

Bourdieu, P. (1990). The logic of practice (R. Nice, Trans.). Stanford, CA: Stanford University Press.

Bourdieu, P. (1991). Language and symbolic power (G. Raymond \& M. Adamson, Trans.). Cambridge: Polity Press.

Bourdieu, P., \& Darbel, A. (1991). The love of art: European art museums and their public. Oxford: Polity Press.

Bourdieu, P., \& Johnson, R. (1993). The field of cultural production: Essays on art and literature. Cambridge: Polity Press.

Bourdieu, P., \& Passeron, J.-C. (1990). Reproduction in education, society and culture (R. Nice, Trans., 2nd ed.). London: Sage.

Bourdieu, P., \& Wacquant, L. (1992). An invitation to reflexive sociology. Chicago, IL: University of Chicago Press.

Bowles, S., \& Gintis, H. (1976). Schooling in capitalist America: Educational reform and the contradictions of economic life. New York, NY: Basic Books.

Bradu, C., Orquin, J., \& Thøgersen, J. (2013). The mediated influence of a traceability label on consumer's willingness to buy the labelled product. Journal of Business Ethics, 1-13.

Brice Heath, S. (2007). Diverse learning and learner diversity in 'informal'science learning environments. Palo Alto, CA: National Research Council Board on Science Education.

Bruner, J. (1960). The process of education. Cambridge, MA: Harvard University Press.

Bruner, J. (1966). Towards a theory of instruction. Cambridge, MA: Harvard University Press.

Bultitude, K., McDonald, D., \& Custead, S. (2011). The rise and rise of science festivals: An international review of organised events to celebrate science. International Journal of Science Education, Part B, 1, 165-188.

Butler, J. (2006). Gender trouble: Feminism and the subversion of identity. New York, NY: Routledge.

Calabrese Barton, A., Ermer, J. L., Burkett, T. A., \& Osborne, M. D. (2003). Teaching science for social justice. New York, NY: Teachers College Press.

Carlone, H. B. (2003). (Re)producing good science students: Girls' participation in high school physics. Journal of Women and Minorities in Science and Engineering, 9, 17-34. 
Carlone, H. B., \& Johnson, A. (2007). Understanding the science experiences of successful women of color: Science identity as an analytic lens. Journal of Research in Science Teaching, 44, 1187-1218.

Crowley, K. (1999). Parent explanations during museum visits: Gender differences in how children hear informal science. Visitor Studies Today! 3(3), 21-28.

Crowley, K., Callanan, M. A., Tenenbaum, H. R., \& Allen, E. (2001). Parents explain more often to boys than to girls during shared scientific thinking. Psychological Science, 12, $258-261$.

Dancu, T. (2010). Designing exhibits for gender equity ( $\mathrm{PhD}$ dissertation). Portland State University, Portland.

Dawson, E. (in press). 'Not designed for us': How science museums and science centres socially exclude low-income, minority ethnic groups. Science \& Education.

Dawson, E., \& Jensen, E. (2011). Towards a 'contextual turn' in visitor studies: Evaluating visiting segmentation and identity-related motivations. Visitor Studies, 14, 127-140.

Delpit, L. (1988). The silenced dialogue: Power and pedagogy in educating other people's children. Harvard Educational Review, 58, 280-299.

Delpit, L. (2006). Other people's children: Cultural conflict in the classroom. New York, NY: New Press.

Department for Culture, Media and Sport. (2011). Taking part: The national survey of culture, leisure and sport. London: Author.

DeWitt, J., \& Osborne, J. (2010). Recollections of exhibits: Stimulated-recall interviews with primary school children about science centre visits. International Journal of Science Education, 32, 1365-1388.

Dierking, L. D., \& Falk, J. H. (2009). Learning for life: The role of free-choice learning in science education. In W.-M. Roth \& K. Tobin (Eds.), World of science education: North America (pp. 179-206). Rotterdam: Sense.

Duensing, S. (2006). Culture matters: Informal science centes and cultural contexts. In Z. Bekerman, N. C. Burbules, \& D. Silberman Keller (Eds.), Learning in places: The informal education reader (pp. 183-202). New York, NY: Peter Lang.

Dumais, S. A. (2002). Cultural capital, gender, and school success: The role of habitus. Sociology of Education, 75, 44-68.

Ecsite-UK. (2008). Inspiration, engagement and learning: The value of Science \& Discovery Centres in the UK, working towards a benchmarking framework. Bristol: Ecsite-UK.

Ellenbogen, K. M. (2002). Museums in family life: An ethnographic case study. In G. Leinhardt, K. Crowley, \& K. Knutson (Eds.), Learning conversations in museums (pp. 81101). Mahwah, NJ: Erlbaum.

European Commission. (2004). Europe needs more scientists: Report by the high level group on increasing human resources for science and technology. Brussels: Author.

Falk, J. H. (2002). The contribution of free-choice learning to public understanding of science. Interciencia, 27, 62-65.

Falk, J. H. (2009). Identity and the museum visitor experience. Walnut Creek, CA: Left Coast Press.

Falk, J. H. (2011). Contextualizing Falk's identity-related visitor motivation model. Visitor Studies, $14,141-157$.

Falk, J. H., \& Dierking, L. D. (2012). Lifelong learning for adults: The role of free-choice experiences. In B. Fraser, K. Tobin, \& C. J. McRobbie (Eds.), Second international handbook of science education (pp. 1063-1079). London: Springer.

Falk, J. H., Osborne, J., Dierking, L. D., Dawson, E., Wenger, M., \& Wong, B. (2012). Analyzing the UK science education community: The contribution of informal providers. London: Wellcome Trust.

Feinstein, N. W., \& Meshoulam, D. (2014). Science for what public? Addressing equity in American science museums and science centers. Journal of Research in Science Teaching, 51, 368-394.

Fenichel, M., \& Schweingruber, H. A. (2010). Surrounded by science: Learning science in informal environments. Washington, DC: National Academies Press.

Foggett, M. (2008). Community consultation at the Dana centre: An audience-led project between London's African-Caribbean community and the Science Museum. London: Science Museum. 
Fraser, N. (1987). Social movements vs. disciplinary bureaucracies: The discourse of social needs (CHS Occasional Paper No. 8). Minneapolis, MN: Centre for Humanistic Studies, University of Minnesota.

Fraser, N. (2003). Social justice in the age of identity politics: Redistribution, recognition, and participation. In N. Fraser \& A. Honneth, Redistribution or recognition? A politicalphilosophical exchange (pp. 7-109). London: Verso.

Fraser, N., \& Honneth, A. (2003). Redistribution or recognition? A political-philosophical exchange. London: Verso.

Freire, P. (1998). Pedagogy of freedom: Ethics, democracy, and civic courage. Lanham, MD: Rowman \& Littlefield.

Freire, P., \& Freire, A. M. A. (1992). Pedagogy of hope: Reliving pedagogy of the oppressed. New York, NY: Continuum.

Garibay, C. (2009). Latinos, leisure values, and decisions: Implications for informal science learning and engagement. The Informal Learning Review, 94, 10-13.

Gayo-Cal, M. (2006). Leisure and participation in Britain. Cultural Trends, 15, 175-192.

Gieryn, T. F. (1998). Balancing acts: Science, Enola Gay and history wars at the Smithsonian. In S. Macdonald (Ed.), The politics of display: Museums, science, culture (pp. 197228). London: Routledge.

Golding, V. (2009). Learning at the museum frontiers: Identity, race and power. Farnham: Ashgate.

Grabill, J. T. (1998). Utopic visions, the technopoor, and public access: Writing technologies in a community literacy program. Computers and Composition, 15, 297-315.

Gurian, E. H. (2006). Civilizing the museum: The collected writings of Elaine Heumann Gurian. Abingdon: Routledge.

Hall, S. (1980). Encoding/decoding. In S. Hall (Ed.), Culture, media, language: Working papers in cultural studies, 1972-79 (pp. 107-116). Birmingham, AL: Umwin Hyman.

Hall, S. (1996). Who needs 'identity'? In S. Hall \& P. Du Gay (Eds.), Questions of cultural identity (pp. 1-19). London: Sage.

Harding, S. (2006). Science and social inequality: Feminist and postcolonial issues. Urbana, IL: University of Illinois Press.

Harding, S. (2008). Sciences from below: Feminisms, postcolonialisms, and modernities. Durham, NC: Duke University Press.

Heath, C., Lehn, D. V., \& Osborne, J. (2005). Interaction and interactives: Collaboration and participation with computer-based exhibits. Public Understanding of Science, 14, 91101.

Holland, D., Skinner, D., Lachiotte, W., Jr., \& Cain, C. (2001). Identity and agency in cultural worlds. Cambridge, MA: Harvard University Press.

hooks, b. (1992). Black looks: Race and representation. Boston, MA: South End Press.

hooks, b. (1994). Teaching to transgress: Education as the practice of freedom. London: Routledge.

Hooper-Greenhill, E. (1994). Museums and their visitors. London: Routledge.

Hooper-Greenhill, E. (1995). Museums and communication: An introductory essay. In E. Hooper-Greenhill (Ed.), Museum, media, message (pp. 1-14). London: Routledge.

Hooper-Greenhill, E., Dodd, J., Creaser, C., Sandell, R., Jones, C., \& Woodham, A. (2007). Inspiration, identity, learning: The value of museums. Second study. An evaluation of the DCMS/DCSF National/Regional Museum Partnership Programme in 2006-2007. London: Department of Culture, Media and Sport.

Ipsos MORI. (2001). Visitors to museums and galleries in the UK. London: Resource, The Council for Museums, Archives and Libraries.

Ipsos MORI. (2006). Renaissance in the regions 2005: Visitor exit survey - Final national report. London: Museums Libraries Archives.

Ipsos MORI. (2011). Public attitudes to science 2011. London: Department for Business, Innovation and Skills.

Ipsos MORI. (2014). Public attitudes to science 2014. London: Department for Business, Innovation and Skills.

Irwin, A., \& Wynne, B. (1996). Introduction. In A. Irwin \& B. Wynne (Eds.), Misunderstanding science? The public reconstruction of science and technology (pp. 1-18). Cambridge: Cambridge University Press. 
Jasanoff, S. (1997). Civilization and madness: The great BSE scare of 1996. Public Understanding of Science, 6, 221-232.

Kelly, G. (2010). Scientific literacy, discourse, and epistemic practices. In C. J. Linder, L. Östman, D. A. Roberts, P.-O. Wickman, G. Ericksen, \& A. MacKinnon (Eds.), Exploring the landscape of scientific literacy (pp. 61-73). New York, NY: Taylor \& Francis Group.

King, H., \& Dillon, J. (2012). Learning in informal settings. In N. Seel (Ed.), Encyclopedia of the sciences of learning (pp. 1905-1908). New York, NY: Springer.

Lawler, S. (2014). Identity: Sociological perspectives. Cambridge: Polity Press.

Lee, O. (1999). Equity implications based on the conceptions of science achievement in major reform documents. Review of Educational Research, 69, 83-115.

Lee, O., \& Buxton, C. A. (2010). Diversity and equity in science education: Research, policy, and practice. New York, NY: Teachers College Press.

Lemke, J. L. (1990). Talking science: Language, learning, and values. Westport, CT: Ablex.

Lemke, J. L. (2001). Articulating communities: Sociocultural perspectives on science education. Journal of Research in Science Teaching, 38, 296-316.

Levin, A. K. (2010a). Straight talk: Evolution exhibits and the reproduction of heterosexuality. In A. K. Levin (Ed.). Gender, sexuality and museums (pp. 201-212). London: Routledge.

Levin, A. K. (Ed.). (2010b). Gender, sexuality and museums. London: Routledge.

Levitas, R. (2004). Let's hear it for Humpty: Social exclusion, the third way and cultural capital. Cultural Trends, 13, 41-56.

Litt, E. (2012). Knock, knock. Who's there? The imagined audience. Journal of Broadcasting \& Electronic Media, 56, 330-345.

Lynch, B. (2001). If the museum is the gateway, who is the gatekeeper? Engage, 11, 12-21.

Lynch, B. (2011). Whose cake is it anyway? A collaborative investigation into engagement and participation in 12 museums and galleries in the UK. London: Paul Hamlyn Foundation.

Lynch, B., \& Alberti, S. J. M. M. (2010). Legacies of prejudice: Racism, co-production and radical trust in the museum. Museum Management and Curatorship, 25, 13-35.

Macdonald, S. (1998). Exhibitions of power and power of exhibition: An introduction to the politics of display. In S. Macdonald (Ed.), The politics of display: Museums, science, culture (pp. 1-24). New York, NY: Routledge.

Macdonald, S. (2002). Behind the scenes at the Science Museum. Oxford: Berg.

Machin, R. (2010). Gender representation in the natural history galleries at the Manchester Museum. In A. K. Levin (Ed.), Gender, sexuality and museums (pp. 187-200). London: Routledge.

Mack, E., Augare, H., Different Cloud-Jones, L., Davíd, D., Quiver Gaddie, H., Honey, R., ... Wippert, R. (2012). Effective practices for creating transformative informal science education programs grounded in native ways of knowing. Cultural Studies of Science Education, 7, 49-70.

Massarani, L., \& Merzagora, M. (2014). Socially inclusive science communication. Journal of Science Communication, 13(2), 1-2.

Matthews, J. (2008). A missing link? The imagined audience, news practices and the production of children's news. Journalism Practice, 2, 264-279.

McCallie, E., Bell, L., Lohwater, T., Falk, J. H., Lehr, J. L., Lewenstein, B., ... Wiehe, B. (2009). Many experts, many audiences: Public engagement with science and informal education. Washington, DC: Center for Advancement of Informal Science Education.

McKinley, E. (2008). From object to subject: Hybrid identities of indigenous women in science. Cultural Studies of Science Education, 3, 959-975.

McNeil, M. (2007). Feminist cultural studies of science and technology. Abingdon: Routledge.

Medin, D. L., \& Bang, M. (2014). Who's asking? Native science, western science, and science education. Cambridge, MA: MIT Press.

Michael, M. (2006). Technoscience and everyday life: The complex simplicities of the mundane. Maidenhead: Open University Press.

Mickelson, R. A. (2003). Gender, Bourdieu, and the anomaly of women's achievement redux. Sociology of Education, 76, 373-375. 
Mortensen, M. F., \& Smart, K. (2007). Free-choice worksheets increase students' exposure to curriculum during museum visits. Journal of Research in Science Teaching, 44, 13891414.

National Science Foundation. (2012). Science and engineering indicators 2012. Arlington, VA: Author.

Nelkin, D. (1995). Selling science. New York, NY: W.H. Freeman and Company.

New York Hall of Science. (2010). The science career ladder: 1986-2010. New York, NY: Author.

Norris, S. P., \& Phillips, L. M. (2003). How literacy in its fundamental sense is central to scientific literacy. Science \& Education, 87, 224-240.

OECD. (2012). Education at a glance 2012: OECD indicators. Paris: Author. Retrieved from http://dx.doi.org/10.1787/eag-2012-en

Ogbu, J. U. (1992). Understanding cultural diversity and learning. Educational Researcher, 21(8), 5-14.

Osborne, J., \& Dillon, J. (2008). Science education in Europe: Critical reflections. London: Nuffield Foundation.

Packer, J. (2008). Beyond learning: Exploring visitors' perceptions of the value and benefits of museum experiences. Curator: The Museum Journal, 51, 33-54.

Palmquist, S., \& Crowley, K. (2007). From teachers to testers: How parents talk to novice and expert children in a natural history museum. Science \& Education, 91, 783-804.

Pedretti, E. (2002). T. Kuhn meets T. Rex: Critical conversations and new directions in science centres and science museums. Studies in Science Education, 37, 1-41.

Phipps, M. (2010). Research trends and findings from a decade (1997-2007) of research on informal science education and free-choice science learning. Visitor Studies, 13, 3-22.

Porter, J. E. (1998). Rhetorical ethics and internetworked writing. Greenwich, CT: Ablex.

Rahm, J. (2008). Urban youths' hybrid positioning in science practices at the margin: A look inside a school-museum-scientist partnership project and an after-school science program. Cultural Studies of Science Education, 3, 97-121.

Rahm, J. (2010). Science in the making at the margin: A multisited ethnography of learning and becoming in an afterschool program, a garden and a math and science upward bound program. Rotterdam: Sense.

Ramey-Gassert, L. (1996). Same place, different experiences: Exploring the influence of gender on students' science museum experiences. International Journal of Science Education, 18, 903-912.

Reay, D. (1998). Cultural reproduction: Mothers' involvement in their children's primary schooling. In M. Grenfell \& D. James (Eds.), Bourdieu and education (pp. 55-71). London: Falmer Press.

Rice, D. (1992). Vision and culture: The role of musuems in visual literacy. In S. K. Nichols (Ed.), Patterns in practice (pp. 144-152). Washington, DC: Museum Education Roundtable.

Roberts, D. A. (2007). Scientific literacy/science literacy. In S. Abell \& N. Lederman (Eds.), Handbook of research on science education (pp. 729-780). Mahwah, NJ: Lawrence Erlbaum Associates.

Roth, W.-M. (2008). Bricolage, métissage, hybridity, heterogeneity, diaspora: Concepts for thinking science education in the 21 st century. Cultural Studies of Science Education, 3, 891-916.

Roth, W.-M., \& Calabrese Barton, A. (2004). Rethinking scientific literacy. New York, NY: Routledge Falmer.

Ruiz-Funes, C. R. (2008). Mediation within science centres and museums. The guides of Universum, México. Journal of Science Communication, 7(4), 1-4.

Sandell, R. (1998). Museums as agents of social inclusion. Museum Management and Curatorship, 17, 401-418.

Sandell, R. (2007). Museums, prejudice and the reframing of difference. London: Routledge.

Sandell, R., Dodd, J., \& Garland-Thomson, R. (2010). Preface. In R. Sandell, J. Dodd, \& R. Garland-Thomson (Eds.), Re-presenting disability: Activism and agency in the museum (pp. xix-xx). Abingdon: Routledge.

Schlereth, T. J. (1992). Cultural history and material culture: Everyday life, landscapes, museums. Charlottesville, VA: University Press of Virginia. 
Shanahan, M.-C. (2009). Identity in science learning: Exploring the attention given to agency and structure in studies of identity. Studies in Science Education, 45, 43-64.

Shanahan, M.-C., \& Nieswandt, M. (2011). Science student role: Evidence of social structural norms specific to school science. Journal of Research in Science Teaching, 48, 367-395.

Shanahan, M.-C., Pedretti, E., DeCoito, I., \& Baker, L. (2011). Exploring the responses of underrepresented students in science to an elementary classroom outreach program. School Science and Mathematics, 111, 131-142.

Simon, N. (2010). The participatory museum. Santa Cruz, CA: Museum 2.0.

Skeggs, B. (1997). Formations of class and gender. London: Sage.

Song, X., \& Zhao, J. (2012). The practice of HPS educational model in science museum. Elementary \& Secondary Schooling Abroad, 11, 60-65.

Stanley, W. B., \& Brickhouse, N. W. (2001). Teaching sciences: The multicultural question revisited. Science \& Education, 85, 35-49.

Stocklmayer, S., Rennie, L., \& Gilbert, J. K. (2010). The roles of the formal and informal sectors in the provision of effective science education. Studies in Science Education, 46, $1-44$.

Storksdieck, M., Haley-Goldman, K., \& Jones, M. C. (2002). Impact of the New York Hall of Science Career Ladder Program on its former participants. Annapolis, MD: Institute for Learning Innovation.

Streicher, B., Unterleitner, K., \& Schulze, H. (2014). Knowledge rooms - Science communication in local, welcoming spaces to foster social inclusion. Journal of Science Communication, 13(2), 1-5.

Tait Lima, M., das Neves, E. F., \& Dagnino, R. (2008). Popularization of science in Brazil: Getting onto the public agenda, but how? Journal of Science Communication, 7(4), 2-8.

Tal, T., \& Alkaher, I. (2010). Collaborative environmental projects in a multicultural society: Working from within separate or mutual landscapes? Cultural Studies of Science Education, 5, 325-349.

Tan, E., Calabrese Barton, A., Gutiérrez, M. V., \& Turner, E. (2012). Empowering science and mathematics education in urban schools. Chicago, IL: University of Chicago Press.

Tenenbaum, H. R., \& Callanan, M. A. (2008). Parents' science talk to their children in Mexican-descent families residing in the USA. International Journal of Behavioral Development, 32, 1-12.

Tervalon, M., \& Murray-Garcia, J. (1998). Cultural humility versus cultural competence: A critical distinction in defining physician training outcomes in multicultural education. Journal of Health Care for the Poor and Underserved, 9, 117-125.

The Association for Science and Discovery Centres. (2010). Assessing the impact of UK Science and Discovery Centres: Towards a set of common indicators. Bristol: Author.

Tissier, D., \& Singh Nathoo, S. (2004). Telling it like it is: Non-user research. Black and minority ethnic engagement with London's museums. London: Strategic Urban Futures.

Tlili, A. (2008). Behind the policy mantra of the inclusive museum: Receptions of social exclusion and inclusion in museums and science centres. Cultural Sociology, 2, 123-147.

Trienekens, S. (2002). 'Colourful' distinction: The role of ethnicity and ethnic orientation in cultural consumption. Poetics, 30, 281-298.

Tunnicliffe, S. D. (2008). Conversations of family and primary school groups at robotic dinosaurs in a museum? What do they talk about? Journal of Elementary Science Education, 20(3), 17-33.

Tunnicliffe, S. D., \& Laterveer-de Beer, M. (2002). An interactive exhibition about animal skeletons: Did the visitors learn any zoology? Journal of Biological Education, 36, 130134.

Uyen Tran, L., \& King, H. (2007). The professionalization of museum educators: The case in science museums. Museum Management and Curatorship, 22, 131-149.

Vygotsky, L. S. (1978). Mind in society. Cambridge, MA: Harvard University Press.

Vygotsky, L. S. (1986). Thought and language. Harvard, MA: MIT Press.

Wellcome Trust. (2008). Millennium science centres impact assessment report. Executive summary. London: Author.

Wertsch, J. V. (1985). Vygotsky and the social formation of mind. Cambridge, MA: Harvard University Press. 
Wertsch, J. V., Minick, N., \& Arns, J. (1984). The creation of context in joint problem solving. In B. Rogoff \& J. Lave (Eds.), Everyday cognition: Its development in social contexts (pp. 151-171). Cambridge, MA: Harvard University Press.

Yalowitz, S., Garibay, C., Renner, N., \& Plaza, C. (2013). Bilingual exhibit research initiative: Institutional and intergenerational experiences with bilingual exhibitions. Washington, DC: Center for Advancement of Informal Science Education.

Yosso, T. J. (2005). Whose culture has capital? A critical race theory discussion of community cultural wealth. Race Ethnicity and Education, 8, 69-91.

Young, I. M. (1990). Justice and the politics of difference. Princeton, NJ: Princeton University Press.

Young, I. M. (2000). Inclusion and democracy. Oxford: Oxford University Press.

Zouaoui, A. (2007). Education, facilitation and inclusion - The Tunisian experience. Journal of Science Communication, 6(2), 1-2. 